Universidad de Lima

Facultad de Comunicación

Carrera de Comunicación

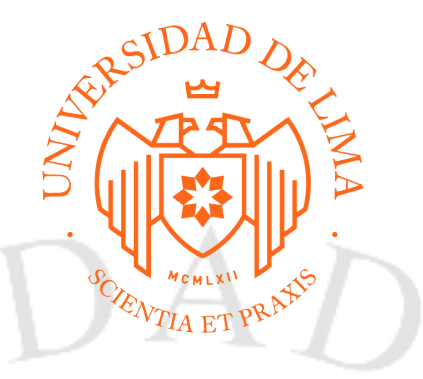

\title{
"Experiencia de creación, escritura y venta de un guion de largometraje para su producción, realización y distribución comercial"
}

Trabajo de Suficiencia Profesional para optar el Título Profesional de Licenciado en Comunicación

Anais Champin Vidal

Código 20092000

Tamara Maria Bravo Lembcke

Código 20092168

Asesor

Giancarlo Cappello

Lima - Perú 


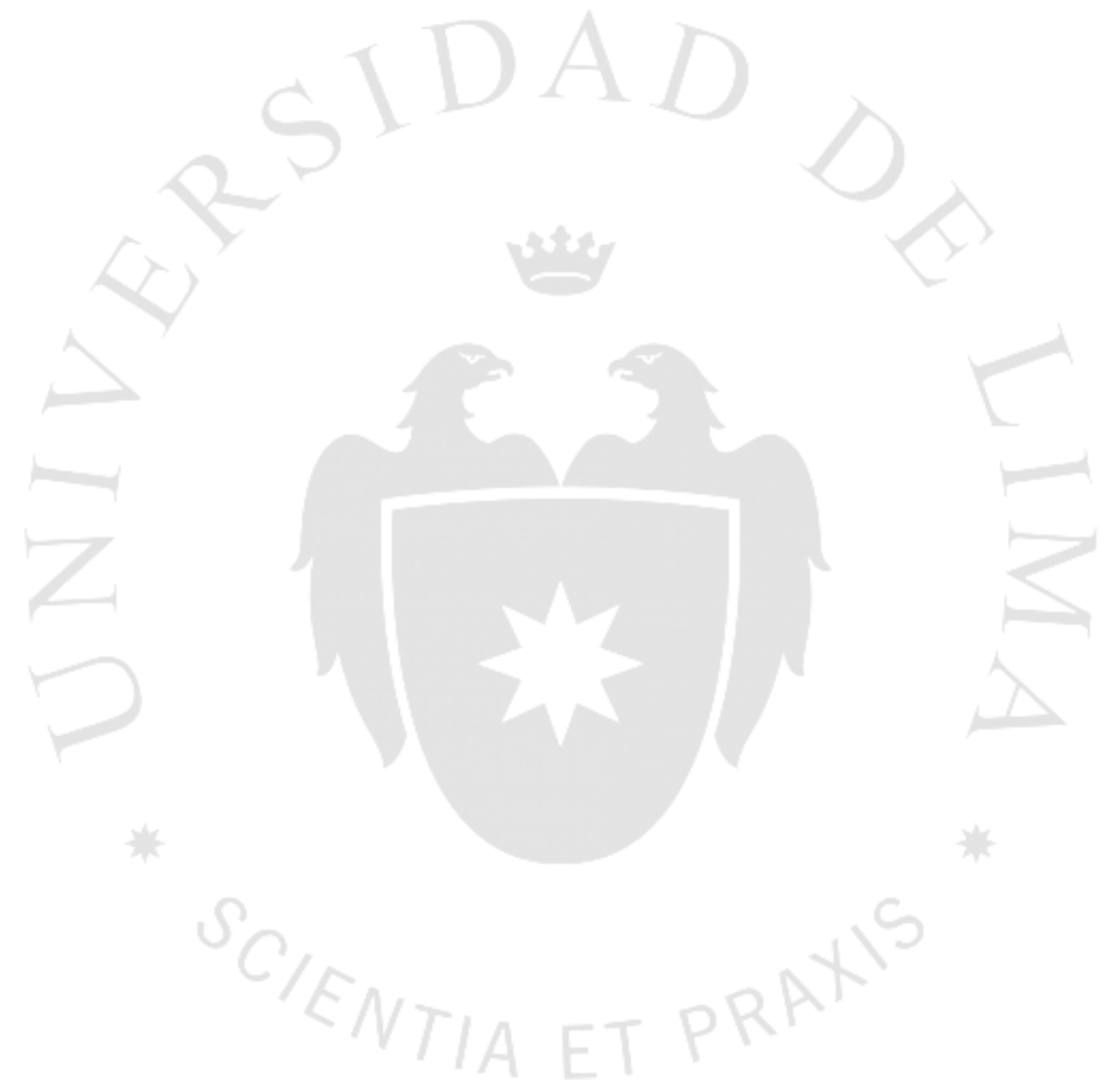


Experiencia de creación, escritura y venta de un guion de largometraje para su producción, realización y distribución comercial 


\section{ÍNDICE}

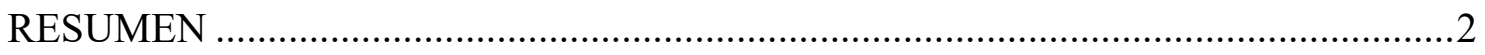

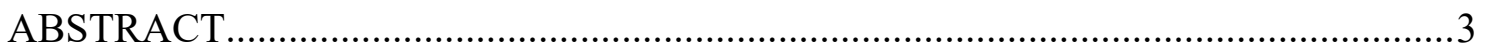

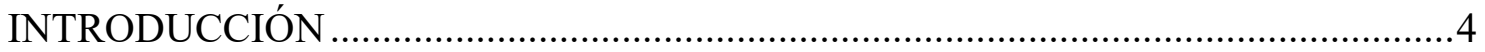

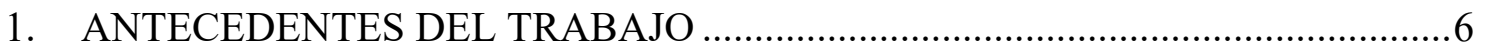

1.1 La comedia: el género preferido por los peruanos ........................................6

1.2 Cine y publicidad: una alianza prometedora .................................................6

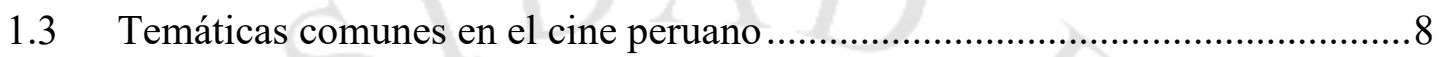

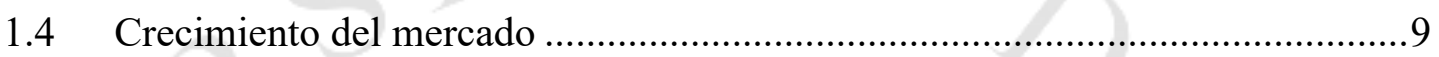

1.5 El guionista en el mercado cinematográfico peruano .................................... 11

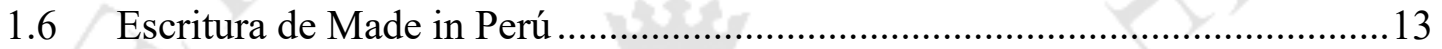

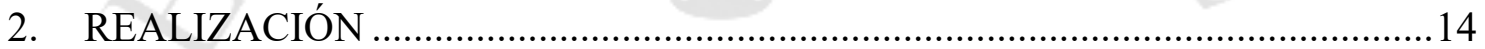

2.1 Fase 1: Documentación y búsqueda de referencias.......................................14

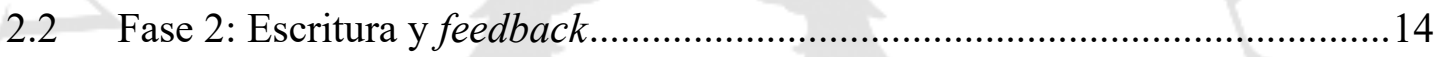

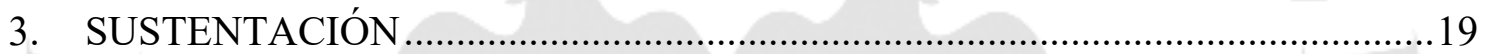

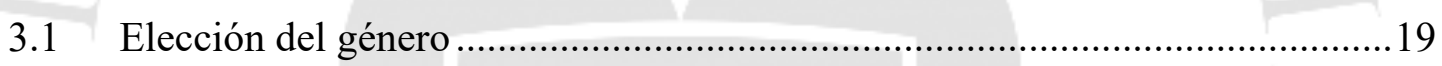

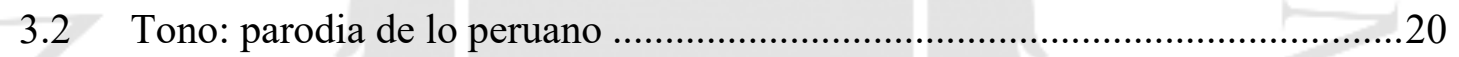

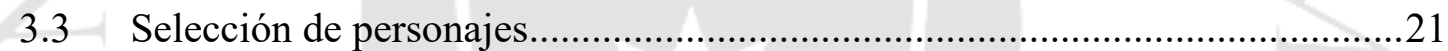

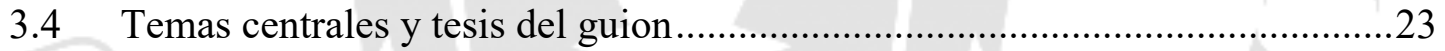

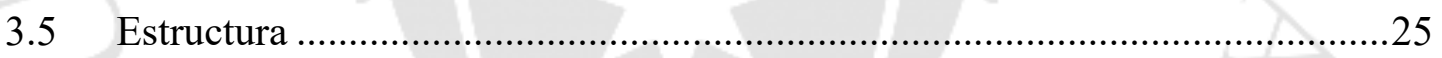

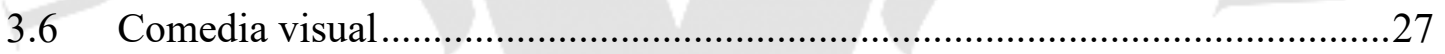

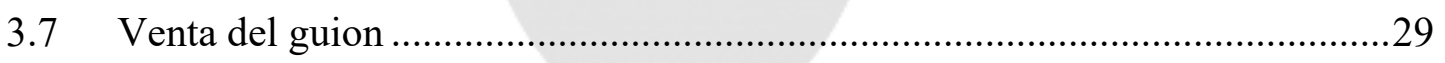

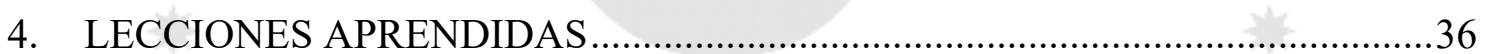

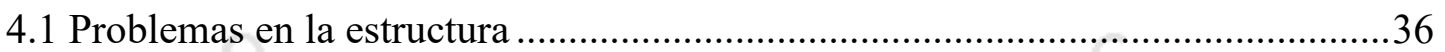

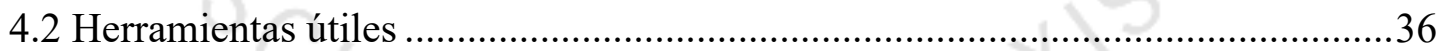

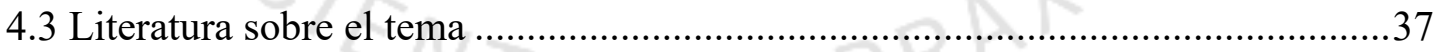

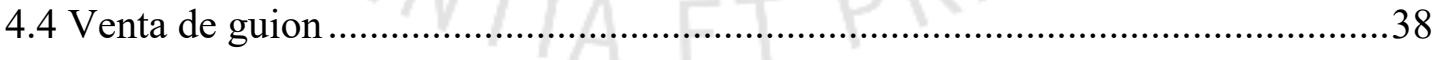

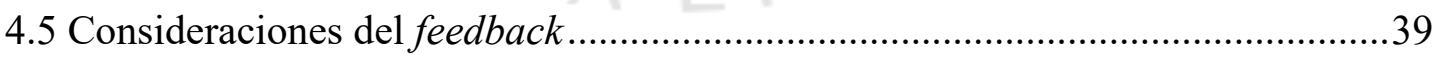

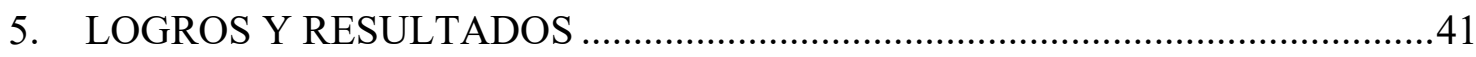

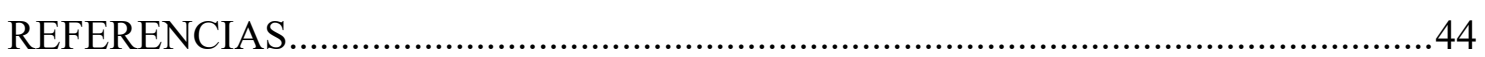




\section{ÍNDICES DE TABLAS Y GRÁFICOS}

\section{Tablas}

Tabla 1.1. Ingreso de taquilla................................................. 10

Tabla 3.1. Cambios en los personajes en diferentes versiones del guion.................33

\section{Gráficos}

Gráfico 1.1. Evolución del número de espectadores de la industria.

\section{Hipervínculos}

Guion en Google Drive. . .46 


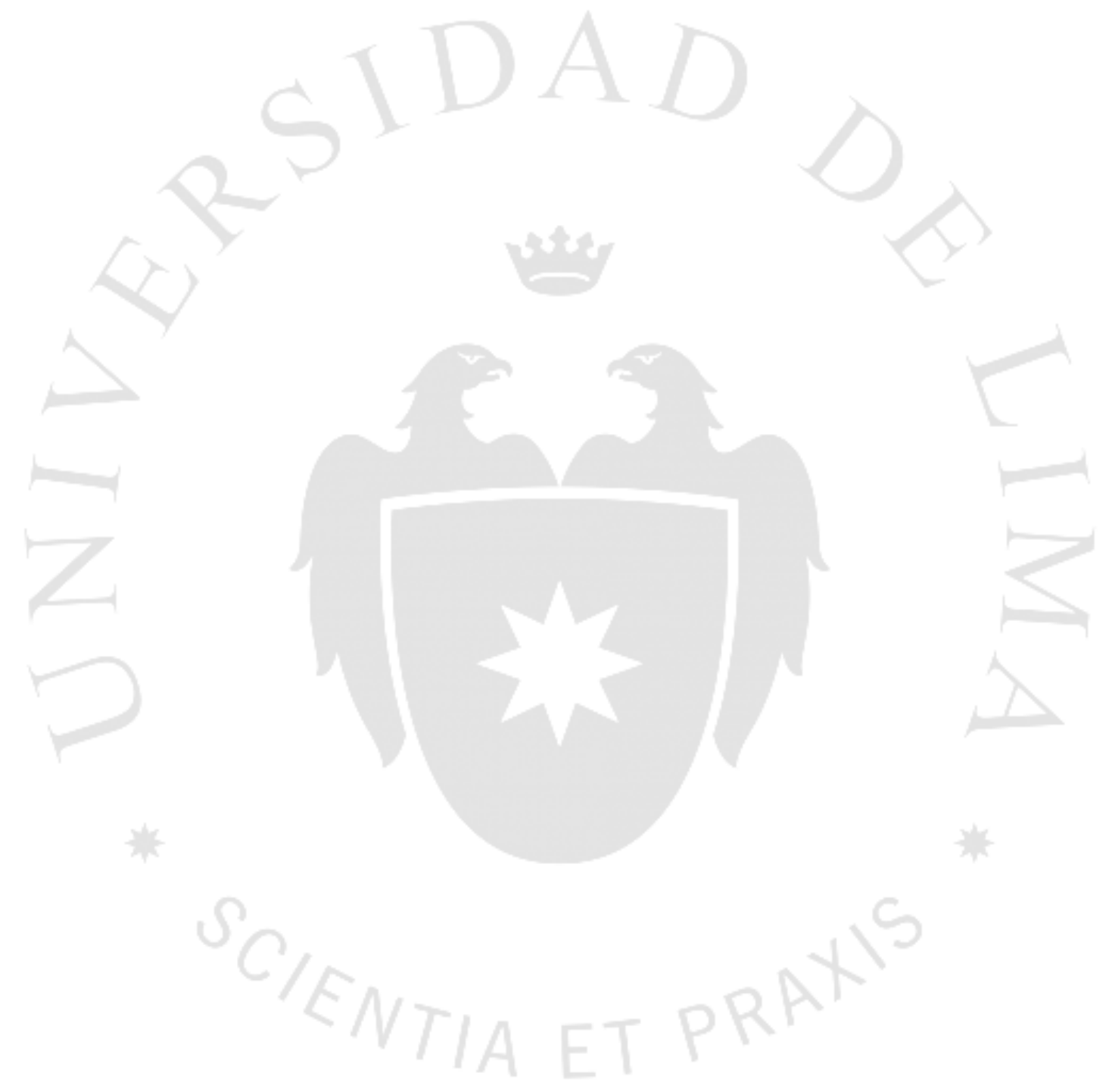




\section{RESUMEN}

Made in Perú es un proyecto de largometraje conceptualizado y escrito por Tamara Bravo y Anaís Champin. Pensado como un producto comercial, se trata de una comedia romántica que basa su humor en lo visual, un recurso muy usado y exitoso en los últimos años, tanto en el país como en el extranjero. Anaís y Tamara investigaron temas como el mercado cinematográfico peruano moderno, la estructura aristotélica de la narrativa y el potencial de una historia sobre choque de culturas y peruanidad. ¿El propósito? Desarrollar un guion de largometraje que pueda ser vendido para su producción, realización y distribución comercial, meta que se logró al cerrar un contrato con una productora independiente. En este documento, se comentan los pasos seguidos para la conceptualización, escritura y venta del guion, se comparten recomendaciones y lecciones que tal vez sirvan a jóvenes aspirantes a guionistas o escritores, quienes quieran embarcarse en un proyecto similar y entrar en el mercado cinematográfico comercial en el Perú.

\section{PALABRAS CLAVES}

GUION - LARGOMETRAJE - PELÍCULA - COMUNICACIÓN - AUDIOVISUAL - PERÚ 


\begin{abstract}
Made in Peru is a feature-length screenplay project conceptualized and written by Tamara Bravo and Anais Champin. Thought as a commercial product, this film aims to be a romantic comedy (rom-com) that bases its humour upon visual resources that have been proven successful and recurring in the last years, both within and outside the country. Anais and Tamara researched subjects such as the modern Peruvian film industry, the Aristotelian narrative structure, and the potential success a story about culture shock and being Peruvian might have. The purpose? To develop a feature-length screenplay that could be sold for its production, realization and commercial distribution; a goal that was met after a contract closure with an independent producer. In this essay, we will comment on the steps followed for the screenplay's conceptualization, writing and sale, and we will share recommendations and lessons that might show useful to young aspiring writers and scriptwriters, who may want to get involved in similar projects and become a part of the commercial film industry in Peru.

\section{KEYWORDS}

SCREENPLAY - SCRIPT - FILM - FEATURE - MOVIE - COMMUNICATIONS AUDIOVISUAL - PERU
\end{abstract}




\section{INTRODUCCIÓN}

Hasta hace un tiempo, Perú era un mercado cinematográfico que por años se desarrolló de forma "autosuficiente" o "autofinanciada" por los directores y creadores de sus propios proyectos audiovisuales. Estos, en algunas ocasiones, conectaban con la crítica internacional y local, pero no complacían totalmente las motivaciones del público general; esto, hasta la llegada de ¡Asu mare! en el 2013, película que estableció un puente entre la producción audiovisual y las marcas locales.

A partir de este momento, empezamos a observar con más frecuencia prácticas como la contratación de guionistas a pedido de clientes, ya sean directores y productores, o una generación de proyectos bajo la modalidad del pitch. Sin embargo, aún se trata de prácticas poco profesionalizadas, en las cuales las metodologías de investigación de mercado o marketing todavía no se hacen presentes al tomar la decisión de realizar proyectos cinematográficos.

En este contexto, decidimos escribir un guion que pudiera transformarse en una

película de corte popular, que tuviera un alcance masivo y que pudiera llenar las expectativas y gustos del consumidor promedio de cine peruano. Intuitivamente, decidimos centrar la historia en temáticas como las costumbres peruanas, las relaciones familiares, las relaciones amorosas, entre otras, con un tratamiento de comedia que es uno de los géneros más populares del país. Paralelamente, decidimos documentarnos con referencias de películas extranjeras similares, en teoría de creación de guion, storytelling, etc. Aunque sabíamos que no se trataba de una fórmula infalible, finalmente logramos vender el guion.

Este trabajo explica una experiencia exitosa de escritura y venta, en la medida que la historia ha podido despertar interés en una productora que la ha comprado. Esta experiencia podría ser útil para otros aspirantes a guionistas que aún enfrentan una industria cinematográfica que no termina de asentarse.

Nuestra experiencia previa fue clave para desarrollar este proyecto. Ambas autoras, egresadas de la Facultad de Comunicaciones de la Universidad de Lima, con enfoques profesionales diferentes pero a la vez complementarios para poder crear este tipo de producto. Tamara cuenta con experiencia de trabajo como asistente de dirección 
en proyectos audiovisuales, en su mayoría publicitarios, y Anaís con experiencia en marketing digital y redacción creativa. Esta experiencia exitosa nos ha motivado a seguir escribiendo en el futuro.

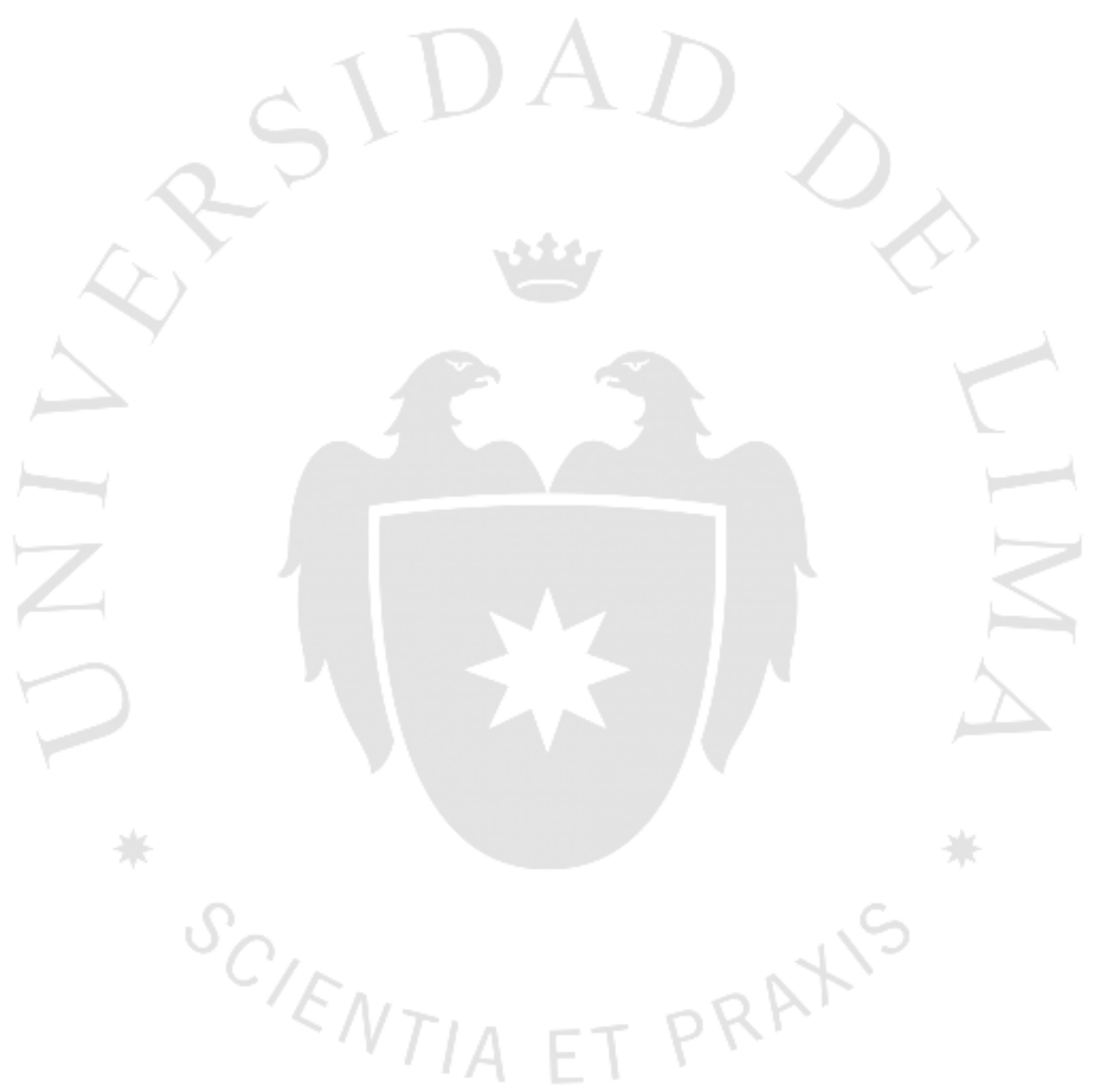




\section{ANTECEDENTES DEL TRABAJO}

\subsection{La comedia: el género preferido por los peruanos}

En el 2017, de las diez películas más taquilleras en el Perú, nueve fueron comedias. En el 2018, 17 de las 32 cintas estrenadas eran comedias (Cine peruano: Más de la mitad de estrenos serán comedias, 19 de enero 2018). Y si hacemos un listado de las películas peruanas más taquilleras de los últimos tiempos, nos encontraremos con películas como Calichín (2016), con 928858 espectadores; Locos de Amor 2 (2018), con 890 261; No me digas solterona (2018), con 868 482; Once machos (2017), con 804 852; Guerrero (2016), con 796 311; y Ceviche de tiburón (2017), con 784 282. A excepción de Guerrero, un drama biográfico sobre la vida del renombrado futbolista Paolo Guerrero, todas las demás películas pertenecen al género de la comedia.

Han pasado seis años desde el estreno de ¡Asu mare! (2013) que, junto con las otras dos películas de la saga — además de A los 40 (2014) y Locos de amor (2016)-, son las únicas que superaron la barrera del millón de espectadores. Ante el incremento de películas peruanas en las salas de cine cada año, la escasa taquilla no se debería a una contracción del mercado ni al desinterés del público, sino a la dispersión de la demanda ante una mayor oferta de películas nacionales que compiten por la atención del público (Análisis de la taquilla del cine peruano del 2018, 7 de febrero de 2019). La preferencia del público nacional por la comedia es explicada por Raúl Licetti, gerente general de la distribuidora New Century Films en el Perú, quien afirma que el peruano prefiere la comedia familiar frente a otros géneros debido al vínculo afectivo que se genera entre personaje y espectador en este tipo de cintas: "La cuota de humor, enredo y la forma de salir de él generan empatía" (CONFIEP, 7 de diciembre del 2018).

\subsection{Cine y publicidad: una alianza prometedora}

Desde el estreno de ¡Asu mare!, hemos visto cómo el cine peruano ha despertado interés en miles de espectadores. La productora Tondero logró romper con la inercia y ha aportado dinámica a la industria cinematográfica en el país, haciendo que marcas, 
empresas y cines apuesten por cintas nacionales. Miguel Valladares, gerente general de Tondero, comentó:

El apoyo que recibimos de empresas privadas fue muy importante; entre las que destacan [están] Brahma, DirecTV, el Británico e Inca Kola. Creo que la publicidad que tuvo ¡Asu mare! hizo que sea un éxito rotundo. Y eso, precisamente, es lo que les falta a muchas películas peruanas: tener promoción (Antes se producían 5 películas al año, esto cambió gracias a las marcas, 14 de junio del 2019).

De esta manera, muchas de los siguientes estrenos en el Perú han contado con esa misma lógica de promoción. A los 40 (2014), también de Tondero, tuvo el apoyo de Pantene, Oral-B, Gillette y Brahma; Japy ending (2014), de Big Bang Films, contó con el apoyo de Lenovo; Viejos amigos (2014), de Mama Okllo Films, contó con el auspicio de la marca Plenitud; Perro guardián (2014), de la productora Señor Z, contó con el apoyo de IPAE, Promart y El Comercio (Las marcas en el cine peruano, 14 de setiembre de 2014). Soltera codiciada (20118), de Tondero, fue auspiciada por Riccadonna, Fuze Tea, Carezza, Halls y Porta; Calichín (2016), de Cine 70 Films, contó con el patrocinio de Entel y el auspicio de Tigre, Radio Capital, Derco Perú y Pavco Perú. La segunda entrega de Once machos (2019) consiguió el apoyo de Punto Visual, Walon, Rústica y Mall del Sur. Y así como ellos, desde hace unos años, cada película que se ha hecho en el país, sea independiente o comercial, ha buscado apoyarse en empresas privadas que apuestan por los proyectos, de manera que los gastos bajen a cambio de canjes, anuncios y lo que se conoce como product placement, que consiste en ver a los clientes y anunciantes dentro de la ficción, a manera de publicidad orgánica.

Es así como, en un contexto en el cual la audiencia está fragmentada, los medios tradicionales están disminuyendo su atractivo publicitario y el streaming sin publicidad aumenta su popularidad, que el cine se convierte - al menos en nuestro país - en una forma novedosa de promocionar productos.

Esta sinergia entre publicidad y cine viene trayendo resultados positivos desde el punto de vista del aumento de la cantidad de producción, el interés de las salas por proyectar material nacional y el impacto en la audiencia peruana. Miguel Valladares señala: 
Cuando nosotros comenzamos, se producían cinco o seis películas al año, que son finalmente las que estaban financiadas por el Estado. Esto ha cambiado a raíz del acercamiento a las empresas privadas y la construcción de una relación con ellos (Antes se producían 5 películas al año, esto cambió gracias a las marcas, 14 de junio del 2019).

\subsection{Temáticas comunes en el cine peruano}

Muchos concuerdan que el éxito del actual cine peruano con ¡Asu mare! se debe a que el público tiene la necesidad de ver una representación y un reflejo de su realidad en el contenido que consume. Este patrón se observa desde la década de 1980 en la televisión, específicamente en los programas cómicos. Al respecto, Luis Peirano y Abelardo Sánchez León (1984) comentan:

Lo saben muy bien los programadores y gerentes de la televisión, lo confirman los ratings de sintonía. Los excelentemente realizados programas extranjeros, como el Show de los Muppets y Benny Hill, no tienen nada que hacer con la sintonía de los nacionales Show de Tulio Loza o Risas y salsa. Ni siquiera el excepcional programa mexicano El chavo del ocho, puede competir con los programas nacionales mencionados. Los peores, indefinidos y mediocres programas de risa y humor hechos en el Perú, tienen por lo menos un rating comparable a este último (Peirano \& Sánchez León, 1984, pág. 27).

Nuevamente, refiriéndose a la saga de ¡Asu mare!, el antropólogo Raúl Castro

resalta entre sus conclusiones cómo los espectadores reaccionan ante "el retrato emocional que encuentran de sí mismos” (Castro, 2017, pág. 38). En el caso de ¡Asu mare!, lo vemos en la historia de ascenso social de Cachín, desde el barrio de Mirones hasta el éxito económico y la realización personal.

Si observamos más de cerca las temáticas de las películas peruanas más exitosas, podemos ver que predominan temáticas de ascenso social (saga ¡Asu mare!), relaciones amorosas (¡Asu mare!, Locos de amor y Calichín) y fútbol (Guerrero, Once machos y Calichín). 


\subsection{Crecimiento del mercado}

A pesar de la creciente popularidad de los servicios de streaming y de la disponibilidad de una gran variedad de nuevos servicios de entretenimiento, el mercado del cine en el Perú sigue creciendo. Solo en el 2018, esta industria movió S/. 428,4 millones, siendo la cadena Cineplanet la empresa con mayor participación en el sector, con el 46\% (Apoyo \& Asociados, 2018). Raúl Licetti, gerente general de la distribuidora New Century Films en Perú, comenta al respecto que "el peruano es un fiel consumidor de cine, gusta de su propio cine y lo estamos viendo en las cifras [...]. En general, es un perfil muy positivo para nuestra industria" (CONFIEP, 7 de diciembre del 2018).

Aunque las salas de mayor concurrencia se encuentran en Lima, estas no forman parte de la Lima moderna. Los locales con mayores ingresos por taquilla son Cineplanet de San Miguel y Mall del Sur, con una recaudación de S/. 14,8 millones y S/. 14,7 millones, respectivamente (Conoce la nueva cadena de cines que iniciará operaciones en Perú, 29 de junio de 2019).

Gráfico 1.1. Evolución del número de espectadores de la industria

\section{Evolución del número de espectadores de la industria (1980-2016)}

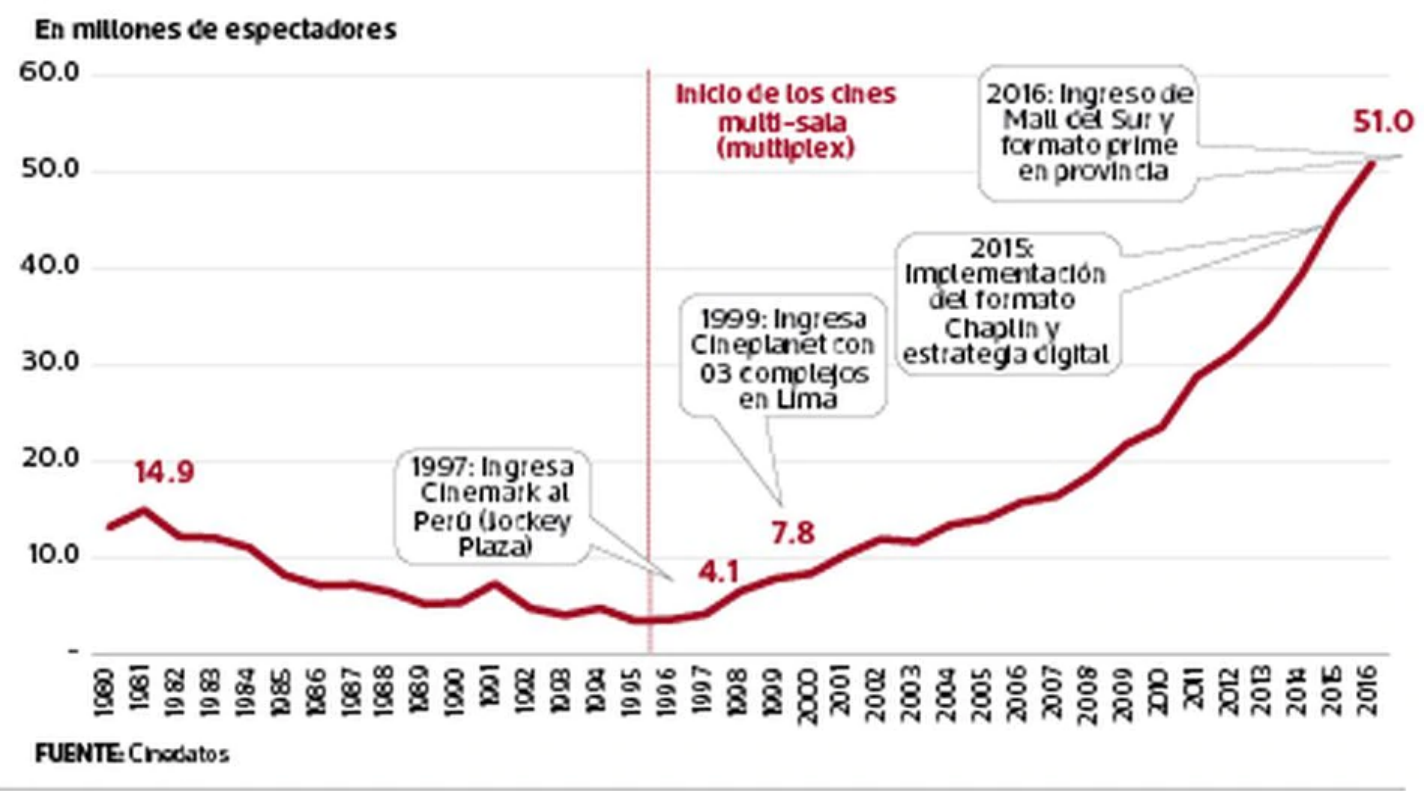

Fuente: Perú Retail 
Tabla 1.1. Ingreso de taquilla

\begin{tabular}{|c|c|c|c|}
\hline \multicolumn{4}{|c|}{ Ingreso de taquilla } \\
\hline & CINES & SALAS & INGRESOS (S/.) \\
\hline 1 & CINEPLANET SAN MIGUEL & 20 & 14865972 \\
\hline 2 & CINEPLANET MALL DEL SUR & 13 & 14769160 \\
\hline 3 & CINEMARK JOCKEY PLAZA & 12 & 12853798 \\
\hline 4 & CINEMARK MEGAPLAZA & 11 & 12851739 \\
\hline 5 & CINEPLANET SAN BORJA & 10 & 11105733 \\
\hline 6 & CINEPOLIS LIMA NORTE & 14 & 10658511 \\
\hline 7 & CINEPOLIS SANTA ANITA & 11 & 9967913 \\
\hline 8 & CINEPLANET PRIMAVERA & 9 & 9678548 \\
\hline 9 & CINEPLANET SALAVERRY & 9 & 8941944 \\
\hline 10 & CINEPLANET ALCÁZAR & 8 & 8530156 \\
\hline
\end{tabular}

Fuente: Perú Retail

Las provincias no se quedan atrás; en total, constituyen la venta de más de 19 millones de entradas (S/. 134 millones). Se destaca el caso de Cusco, donde se vende más de un millón de entradas al año. Jorge Licetti, CEO de New Century Films, ve el futuro del cine como una industria que promete seguir creciendo:

Hace tiempo solo teníamos 8 millones de espectadores al año en Perú. Hoy día tenemos más de 50 millones de espectadores al año. El cine local ha mostrado un crecimiento en capacidad de competir contra películas internacionales. No solo en Perú sino en otros países de Latinoamérica: películas locales pueden ser tan o más competitivas que las internacionales (El negocio del cine en provincias ha tenido un crecimiento "explosivo" según New Century Films, 16 de noviembre de 2018). 


\subsection{El guionista en el mercado cinematográfico peruano}

Según Gonzalo Rodríguez Risco, conocido guionista y dramaturgo peruano, no existe un círculo o directorio de guionistas. Es un espacio al que se ingresa por contactos o recomendaciones. Él ha trabajado por más de diez años como dramaturgo y, desde hace cinco, aproximadamente, ingresó al mundo del cine con la película de su hermano Daniel Rodríguez Risco, El vientre (2014). Desde entonces, ha trabajado en otras películas como No estamos solos (2016), Siete semillas (2016), Una Navidad en verano (2017) y Rómulo y Julita (2020). Aun así, Gonzalo Rodríguez Risco consigue sus proyectos por medio de recomendaciones de productores, directores u otros miembros del rubro.

Según palabras de Rodríguez Risco, no es común que un guionista escriba un guion de largometraje completo sin tener un contrato de antemano. "Mi regla general es: nadie escribe un guion a menos que ya tenga una productora que lo quiera hacer. Lo que suelen vender son sinopsis, ideas. Una vez que te pagan, ahí recién escribes el guion” (G. Rodríguez Risco, comunicación personal, 29 de octubre del 2019).

Con la intención de ahorrar tiempo, trabajo y no arriesgarse en gran magnitud, se busca a una empresa productora que se interese por la trama de la película y, una vez cerrada la compra, empieza el proceso de escritura, pasando por una escaleta y luego un guion. Todo el proceso se acuerda mediante un contrato de trabajo, el cual debe ser negociado por cada guionista bajo su propio criterio, pues no existe un contrato base en Indecopi, y la falta de sindicalización implica que no hay una tarifa acordada ni reglamentaciones o cláusulas prediseñadas para esta clase de trabajos.

Según Rodríguez Risco, "vivimos en un mundo de contactos y de abrirse puertas” (G. Rodríguez Risco, comunicación personal, 29 de octubre del 2019). Esa es la manera de adentrarse en el negocio. Muchos novatos suelen tener un cortometraje, o un guion corto como carta de presentación, ideas escritas a modo de sinopsis o conceptos, de manera que se pueda ilustrar su talento. Los productores no leerán un guion completo sin saber con qué clase de persona se están involucrando, por lo que una carta de presentación suele ser indispensable.

Un primer guion suele costar aproximadamente US\$10 mil. Según Rodríguez Risco, a este precio se ha ido llegando gracias a compartir experiencias en el intento de sindicalizarse y formar una organización de escritores que puedan apoyarse unos a otros 
en el medio cinematográfico, donde ni los mismos compradores saben realmente cuánto pagar.

Podemos poner como ejemplo a Tondero, productora cinematográfica, la cual no paga más de US\$ 10 mil por guion, sin reparar en la experiencia o el reconocimiento del guionista. Esto es considerado un problema por los guionistas más experimentados, pues Tondero es la productora con mayor presupuesto anual para películas, además de ser la más renombrada. Muchos guionistas apuntan a venderles un guion, pero es difícil aceptar las cifras actuales, las cuales hasta el momento aparentan ser inamovibles.

Para lograr una ganancia mayor por el trabajo invertido - el cual suele durar aproximadamente un año, entre desarrollo de historia, guionización y cambios-, los guionistas suelen acordar con la empresa productora un "bono de éxito", el cual sirve como reemplazo de las regalías por el estreno de la película. Dicho bono certifica que, una vez recuperada la inversión de la empresa en la realización de la película, por cada cierto número de espectadores e ingresos previamente acordado, el guionista gana un porcentaje o una cifra fija. Este acuerdo no solo permite una mayor ganancia sino que, según lo conversado con Rodríguez Risco, ayuda a mantener un sentido de pertenencia en cuanto a la película, en lugar de dejar el guion en manos de un tercero y presenciar desde lejos su desarrollo y, con ilusión, su éxito.

La Sociedad General de Autores y Escritores de España mantiene un criterio no oficial orientador en materia de honorarios para guionistas, que data del 2016, y precisa que un largometraje cuesta - entre guion, sinopsis y tratamiento - aproximadamente $€$ 55 mil, lo que demuestra que el mercado en nuestro país tiene aún un largo camino por recorrer.

Dadas las complicaciones y obstáculos que los guionistas encuentran en el mercado cinematográfico comercial peruano, muchos optan por escribir y dirigir sus propias películas. Lamentablemente, el cine independiente cuenta con sus propias barreras y problemas, ya que implica buscar inversión, equipo técnico y distribución de manera individual. 


\subsection{Escritura de Made in Perú}

En el 2017, nosotras hacíamos trabajo freelance de community manager para la casa realizadora Cine 70. Entre las cuentas que gestionábamos se encontraba el fanpage de Facebook de la película Calichín (2016). Como parte del ejercicio de generar contenido para mantener vigente la página, decidimos crear una parrilla de contenidos utilizando los gags más relevantes de la película pero, al ver la película, se encontró que esta, a pesar de tener un buen manejo de realización, fotografía y actores, tenía problemas en la historia para definir el tono de la película - por momentos comedia, por momentos melodrama-, no tenía estructura aristotélica clásica y los momentos de comedia no estaban bien definidos — solo se encontraron tres gags fácilmente identificables—.

A pesar de los problemas de la cinta, esta había contado con una gran asistencia e, incluso un año después de estrenada, llegaban mensajes y comentarios de personas tratando de interactuar con Calichín (el personaje principal).

Debido a esto, comprendimos la forma en que gran parte del público buscaba identificarse y verse reflejado en las cintas que consumían. Vimos como una oportunidad la idea de generar un guion que exponga de forma central la peruanidad. Planteamos una situación común en nuestra sociedad: peruanos casándose con extranjeros a pesar de las diferencias culturales. 


\section{REALIZACIÓN}

\subsection{Fase 1: Documentación y búsqueda de referencias}

El proceso de escribir el guion empezó de una forma desordenada. Empezamos, oficialmente, en setiembre del 2017. La primera vez que nos juntamos para escribir, esbozamos las diez primeras páginas, pero sin haber hecho una escaleta ni determinado exactamente el logline. Por eso, decidimos darle una pausa a la escritura para documentarnos mejor sobre cómo estructurar la historia.

Ya que la historia trataba sobre un joven que solo habla inglés en un contexto en el cual todos hablan español, buscamos referencias de películas y series que manejaran ambos idiomas, como Everybody Loves Somebody (2017), La casa de las flores (2018), entre otras.

Buscamos otras películas del género comedia que abordaran las diferencias culturales, el romance y los problemas familiares. La película en la que nos inspiramos especialmente fue My Big Fat Greek Wedding (2002), cuya trama versa sobre Fotoula "Toula" Portokalos, una mujer de ascendencia grecoamericana que se enamora de un muchacho estadounidense llamado Ian Miller. Durante la película, los protagonistas tienen que luchar por vencer las diferencias culturales, con lo cual se abordan temas de relaciones familiares y tradición.

\subsection{Fase 2: Escritura y feedback}

Nos organizamos para escribir el guion, reuniéndonos una o dos veces por semana por las noches, luego de salir de trabajar. Ambas con laptops, hablando y escribiendo simultáneamente en un documento compartido en Google Drive. Paralelamente, trabajamos otros documentos con notas e ideas sueltas, detalles de la biografía de algunos personajes importantes, storylines - que, curiosamente, creamos luego de haber avanzado con la primera versión-. 
La primera versión tuvo como protagonista a Natalia y empezaba con más escenas en EE.UU. Luego de hablar con el director José Carlos García, a quien solo se le había contado los puntos centrales de la historia, nos comentó que sería mejor tener de protagonista a Jake, otro de los personajes. Hicimos el cambio, pero no quedamos conformes con el resultado.

El primer borrador fue terminado en diciembre de 2017. En esta primera versión, con Jake en el papel protagónico, teníamos como apertura de la película una secuencia de escenas que lo mostraban en un día normal en la ciudad de Filadelfia, al día siguiente de haberle pedido matrimonio a Natalia. En su oficina, luego de conversar con sus compañeros de trabajo, se dio cuenta de que no conocía a la familia de Natalia y tampoco sabía algo sobre el Perú. Por su parte, Natalia sobre el compromiso da la noticia a sus padres y ellos la obligan a visitarlos para que les presente a su novio, lo cual toma por sorpresa a Jake.

La pareja viaja a Lima para conocer a la familia e inmediatamente se ven abrumados por los escandalosos parientes de Natalia. Estos los obligan a mover la fecha de la boda y celebrarla en Lima, a lo que Jake acepta sin querer al no saber hablar español. Lo que seguía era una serie de situaciones cómicas en las que veríamos a la madre y las tías de Natalia tomando el control de la ceremonia de matrimonio, para consternación de la novia, mientras Jake trataba sin éxito de ser aceptado por la familia. La relación llegaba a un quiebre luego de que los padres de Jake, quienes habían viajado al Perú para la boda, son víctimas de un ataque de alergia ocasionado por el culantro que echó la madre de Natalia a la comida por error.

La paciencia de Jake llega a su límite y termina el compromiso y, de paso, la relación. Por suerte Giannine, la tía "moderna” de Natalia llega de viaje justo a tiempo, para motivarla a arreglar las cosas y recuperar a su novio, por lo que ella va a buscarlo. Por su parte, los padres de Jake, ya recuperados, lo motivan a hacer lo mismo, por lo que ambos se encuentran y solucionan sus diferencias. Finalmente Natalia, con la ayuda de su tía y de su hermana, toman las riendas de la boda y logran organizar una ceremonia y una fiesta que unen las culturas peruana y estadounidense. Natalia y Jake se casan y ambas familias, ahora unidas, celebran a los nuevos esposos.

Dimos a leer el guion a Gabriela Champin (hermana de Anaís Champin), egresada de arquitectura y sin conocimientos exhaustivos de lenguaje audiovisual o 
creación de guiones, para que nos dé sus primeras impresiones. Le pareció una idea original, gustó de la historia y las situaciones de comedia que presentamos. Por tal motivo, confiamos en que la idea podía tener potencial.

Hicimos algunos cambios menores y en febrero del 2018 lo presentamos a Mauricio Chichizola — egresado del New York Film Academy y de la Universidad Peruana de Ciencias Aplicadas (UPC) en la carrera de comunicación audiovisual, y actualmente asistente de dirección de la casa realizadora Kubrick-. Dada su experiencia y conocimientos del rubro, nos dio un feedback mucho más técnico y severo. Entre los comentarios positivos al guion, resaltó que este exponía el problema en los primeros cinco minutos, nos comentó que las diez primeras páginas eran nuestro punto más fuerte, y le agradó que contenga comedia visual.

En relación con el feedback negativo, nos comentó que había algunos problemas con el tono de voz y con la gran cantidad de personajes en la historia que no estaban completamente delineados, que no se sentía una transformación en los personajes principales, y que los sentía muy pasivos —especialmente a Jake-; uno de los personajes, la tía Giannine, quedaba como un recurso deus ex machina, ya que sus menciones previas a su aparición pasaban casi desapercibidas, apareciendo milagrosamente para solucionar los problemas de la pareja.

Nos recomendó ver algunas películas que marcaban bien las situaciones de comedia y los motivos de los personajes, como Shrek 2 (2004) que, por ejemplo, explota de forma adecuada el conflicto entre el protagonista y su suegro.

Decidimos incorporar la mayoría de cambios recomendados por Mauricio Chichizola y tuvimos lista la tercera versión del guion para marzo del 2018. En esta, intentamos involucrar un poco más a Giannine y hacer más evidente que su llegada era esperada. Intentamos definirla de manera tal que su ayuda, al final, no se sintiera fuera de lugar. Por su parte, los protagonistas tomaban un poco más las riendas de la situación; Natalia pasaba por una lucha interna más evidente sobre lo que quería y sentía que era correcto al aceptar las locuras de su familia, mientras que el arco narrativo de Jake se sentía más pronunciado al verlo intentar, de manera más activa, integrarse a la familia y ganarse la aceptación del padre de su novia.

En ese mes, presentamos la nueva versión a Matías Jochamowitz, graduado de Le Cordon Bleu, para recibir el feedback de alguien fuera del rubro. En general, la historia 
y las situaciones de comedia le parecieron buenas. Nos propuso algunos cambios en ciertos detalles, como los nombres de los personajes o algunas partes de los diálogos.

En mayo del 2018, presentamos el guion a José Carlos García, director de publicidad y de cine con más de diez años de experiencia en el medio. Entre el feedback positivo, nos comentó que la historia tenía buenos gags y buenas salidas para los personajes, que el guion estaba bien "dialogado", y que los personajes principales tenían potencial. Entre el feedback negativo, nos comentó que las escenas parecían sketches, que faltaba una línea narrativa clara y una evolución de los personajes durante la historia. Jake y Natalia eran muy pasivos, por lo que nos recomendó darles una línea narrativa en la que Jake buscara acoplarse a la familia de sus suegros y Natalia trataba de sabotear la boda que su mamá estaba organizando. Por otro lado, nos dio la idea de que Leonardo, el padre de la novia, también sea más activo y trate de terminar el compromiso de su hija de maneras más evidentes. Su recomendación fue desarrollar mejor la escaleta para que cada escena tenga un propósito. Por otro lado, nos recomendó como referencia de película My Happy Family (2017), dirigida por Nana Ekvtimishvili.

Para nuestra nueva versión, cambiamos el inicio con el objetivo de alejarnos del cliché. En lugar de tener una secuencia del mundo ordinario de Jake y Natalia, creamos una fiesta de compromiso en EE.UU. con amigos y amigas de los novios. En ella, Jake conversaría con sus amigos sobre temas económicos, de lo que se desprendería que Jake estaría por conseguir un proyecto de trabajo que le daría todas las facilidades para pagar el matrimonio. Más adelante en la historia, se revelaría que Jake pierde el proyecto, lo cual significa que no podría pagar la boda soñada por Natalia, por lo cual él deja que su futura suegra tome las riendas de la ceremonia de matrimonio, pensando que así tal vez no tendría que gastar tanto dinero, y que podría ocultarle la verdad a Natalia sin mayores consecuencias. Además, agregamos un personaje: Max, amigo de la infancia de Natalia, a quien el padre de esta última invita a todos los eventos familiares con la idea de que enamore a su hija y así lograr que ella se quede en el Perú, y se case con un peruano en lugar de casarse con Jake y regresar a EE.UU. Luego se descubriría que Max en realidad es homosexual, y que nunca estuvo interesado en Natalia sino en Jake.

Estos cambios generaban un hilo en la historia que lograba que nuestras escenas no parecieran arbitrarias. Además, eliminamos al personaje de Giannine e hicimos que sea Natalia misma quien, con ayuda de su hermana, logre finalmente tomar el control del 
matrimonio y hacerlo a la manera que quería, sin sucumbir a la presión de su madre y sus tías.

En julio del 2018, enviamos el guion a Rodrigo Chávez y a José Miguel Vizcarra, ambos egresados de la carrera de comunicaciones de la Universidad de Lima. En la reunión que tuvimos con ellos, Rodrigo Chávez nos hizo comentarios centrados en la estructura, recomendándonos concentrarnos separar la escaleta en nueve unidades de acción. Nos comentó que la mejor manera de estructurarlo sería pensando en la forma “PERO (acción) - ENTONCES (acción)". Además, nos comentó que deberíamos equilibrar la escena introductoria, ya que mucha de la acción sucedía en EE.UU. y no se relacionaba con el problema central de la historia; aunque podría satisfacer los criterios de la comedia, no alimentaba la trama.

En agosto del 2018, validamos el guion con tres personas más, todas sin expertise audiovisual, que no nos recomendaron cambios significativos y seguían sintiéndose identificados con la historia. Ese mismo mes, enviamos el guion a Ulises Ríos, productor audiovisual en Kandu Films y exasistente de dirección en Cine 70. Nos recomendó algunos cambios menores, pero parecía que los problemas más graves de estructura y orden estaban solucionados. Por tal motivo, decidimos empezar a enviar el guion a perfiles de mayor peso en el rubro. 


\section{SUSTENTACIÓN}

\subsection{Elección del género}

Se eligió el género de comedia ya que este resultaba comercialmente interesante, y podría asegurar una buena taquilla al comprador pues es un género que, históricamente, ha atraído al gran público.

Se eligió la idea de la relación entre una mujer peruana y un hombre estadounidense porque, mediante el contraste de ambas culturas, podíamos generar un contexto adecuado para resaltar elementos de identidad nacional, además de mostrar situaciones de comedia siguiendo la teoría de la incongruencia. Esta vertiente, planteada por el filósofo Kant, trata de explicar cómo algunas situaciones causan humor debido a que observamos dos o más elementos opuestos o incompatibles, o que no encajan juntos. En nuestro caso, las costumbres peruanas frente a las costumbres estadounidenses.

Esta fórmula, en la que uno de los novios es presentado a la familia del otro, vistos como personajes incompatibles obligados a unirse, ha sido utilizada exitosamente repetidas veces en Hollywood. Por eso, quisimos recrearla adaptada a la realidad de nuestro país, estrategia que ha funcionado muy bien para películas peruanas como la saga ¡Asu mare! El sociólogo Alexander Huerta Mercado comenta:

La saga ¡Asu mare! toma narrativas que los humanos hemos disfrutado en forma mitológica, narrativas populares, cuentos, melodramas y, claro, en el cine. Lo novedoso es el ambiente que deja de ser principesco, idílico o hollywoodense y pasa a construirse en una entrañable urbanización popular (Mirones) donde, entre patios interiores, escaleras de edificios, cocinas con comedor pequeño y televisor incorporado se desarrollan las aventuras de Carlos (Cachín) en su camino del héroe para lograr la trascendencia (Huerta Mercado, 2019, pág. 34).

En esta etapa inicial, nuestro objetivo principal fue buscar la identificación de la audiencia con situaciones que pudieran reconocer como suyas. 


\subsection{Tono: parodia de lo peruano}

Se decidió generar una comedia en la que, principalmente, se parodiase la peruanidad mediante el hilo conductor de la experiencia de un extranjero (Jake) viviendo el día a día con una familia peruana de clase media.

Algunas secuencias claves fueron la experiencia de Jake con las comidas y bebidas locales. Esta no siempre fue retratada de forma positiva sino como experiencias fallidas; por ejemplo, al comer cuy, ají y sangrecita, o que la mamá de Jake (Carol) se embriague con pisco sour. También se refleja en secuencias que permiten visualizar a Lima como una ciudad no precisamente amigable y turística, como cuando Natalia y Jake, recién llegados de EE.UU., son testigos de cómo Tito tiene un altercado violento con otro conductor mientras van camino a casa de Natalia.

Este tipo de secuencias responden a lo que muchos especialistas denominan "humor agresivo" o de burla que los peruanos consumimos desde hace mucho tiempo. Al respecto, Huerta Mercado, dedicado a estudiar extensamente el humor nacional, comenta:

A pesar de que "Trampolín a la Fama" era un espacio dedicado a los concursos, Sánchez León y Peirano lo incluyen en su obra de "humor en la televisión" (Peirano y Sánchez León: 1984) pues el espacio era evidentemente lúdico y fue el paradigma de lo que se vendría en el humor televisivo: la sociedad viéndose a sí misma y burlándose de sí misma. Hay una autoconciencia de no encajar en los valores tanto estéticos como morales que maneja el discurso oficial y es a través de la exageración propia del humor que no sólo es subversiva (y de ahí la sorpresa humorística) con respecto al discurso formal (fluyen contenidos de agresividad, racismo, machismo de manera libre y no cuestionada) sino también consciente de la distancia entre lo oficial y lo popular (lo grotesco o feo se define en función de lo que sería considerado bonito por el discurso oficial revelando una realidad distinta a la idealizada). El humor compartido, la burla hacia "el otro" también contribuirá a la formación de una comunidad que comparte la risa (Huerta Mercado, 2004). 


\subsection{Selección de personajes}

Tuvimos que decidir quién sería el protagonista de nuestra historia, ¿Jake o Natalia?

Nuestra primera elección fue naturalmente hacia Natalia, pues nos era más fácil identificarnos con ella: mujer, millennial, peruana. El problema al empezar a escribir nuestra historia fue hacer que su personaje sea agradable, a pesar de su rechazo inicial hacia lo peruano. Muchas veces parecía fría, superficial e incluso, por momentos, racista. Luego de conversar con José Carlos García (ver capítulo 2), optamos por seguir su recomendación y convertir a Jake en nuestro protagonista, pero esto también trajo problemas. Escribir una película en español en la cual el personaje principal habla otro idioma y maneja muy pobremente el primero, nos traía complicaciones difíciles de solucionar. Cada escena que Jake debía manejar se convertía en una lucha de lenguajes y, a su vez, transformaba al protagonista en un personaje pasivo que veía la historia evolucionar a su alrededor sin poder hacer nada al respecto. Fue por esto que volvimos a darle una oportunidad a Natalia en el papel protagónico. Con la idea de crear a un personaje relacionable y divertido, y de evitar caer en el clasismo o el rechazo a la peruanidad, definimos a Natalia como una mujer fuerte e independiente que está acostumbrada a hacer las cosas a su manera, de modo que al encontrarse con el carácter fuerte y dominante de su madre, no sea lo peruano lo que le genera la incomodidad sino la lucha de poderes de la cual había huido al irse a estudiar a EE.UU. Esto nos abrió las puertas a una infinidad de posibilidades en cuanto a chistes y gags, pues lo ofensivo quedaba de lado y ya teníamos una protagonista que podía cargar con la historia sin mayor conflicto.

Por otro lado, para evaluar cómo serían los personajes secundarios, utilizamos personajes arquetípicos de la sociedad peruana. Para los autores Luis Peirano y Abelardo Sánchez León, los personajes de los programas cómicos de televisión resumen los arquetipos culturales básicos del país. Y en eso se basa su éxito. Ellos comentan al respecto:

Como reflejo y versión de la realidad, la programación televisiva no puede negar las diferencias que existen en el país. Presentarlas será una obligación para la cual, recurre, de inmediato, a los prejuicios más valiosos del sistema cultural. A partir de ellos, los programas cómicos se convierten en los mejores exponentes de un 
doble propósito: de un lado, buscar la identificación y el seguimiento de las audiencias populares a través de distintas vías, para señalar las diferencias y el derecho a una autoafirmación cultural de quienes se sienten distintos por razones históricas, económicas y sociales: de otro lado, y de manera inmediata, busca integrar las diferencias presentadas a partir de una visión que se apoya en los prejuicios y estereotipos heredados del ordenamiento tradicional, reformulados por la machacada e imperiosa necesidad de construir una nación a como dé lugar, combinación a través de la cual se asignan valores y normas que no es posible rehuir (Peirano y Sánchez León, 1984, pág. 304).

Por ello, recurrimos a personajes que representen arquetipos de la sociedad peruana, más que personajes multidimensionales. Mercedes, como la "mamá gallina" sobreprotectora y controladora; Aurelio, como el padre de valores tradicionales, conservador, proveedor y machista; Tito, encarnando los valores peruanos más tradicionales; Yvette, como la encarnación de feminidad sexualmente explícita, casi imitando al estereotipo de la vedette; Gabriela, como la feminidad más intelectual; y Rafo, la oveja negra y descarriada, el marihuanero, el "quemado" del grupo.

Reforzando este punto, aunque cargado de una opinión negativa, Jaime Herrera, columnista del blog Humor S.A. del diario Gestión comenta:

Asimismo, Risas y salsa utiliza de forma recurrente la fórmula del café-concert típico argentino de los 70s (esto lógicamente sucede porque el argentino Guillermo Guille fue director y productor del programa), está fórmula básica incluye la presencia de estereotipos: la gorda, el feo, el enano, el gay, el vivo del barrio y la vedette, a ellos habría que añadir el elemento "tropicalizado" del modelo: el cholo, y listo tenemos "el mix perfecto" para crear un programa cómico. He aquí otra pista: si hay una mix de los estereotipos anteriormente mencionados, es gracioso. De ahí también surge el uso abusivo que se hace de los gays exagerados como recurso humorístico en Perú (Herrera, 31 de diciembre de 2015).

Sin embargo, también encontramos que romper estereotipos nos fue útil como salida novedosa para generar plot twist y situaciones de humor. Tal es el caso del personaje de Max. Típicamente, en los programas de televisión o películas populares los homosexuales se muestran femeninos, sexualmente explícitos o indefensos. En el caso 
del personaje que creamos, se trata de un hombre que es percibido como exitoso, que se mueve naturalmente en ambientes masculinos y que, incluso, muestra su hombría de forma triunfante al ser un buen jugador de fútbol.

\subsection{Temas centrales y tesis del guion}

Nuestra historia aborda temas como las diferencias culturales y sociales, la xenofobia, las relaciones interculturales, los polos opuestos, la familia y el amor; todos ellos, temas recurrentes en el cine y las series de televisión.

Shakespeare usó estos temas en Romeo y Julieta, en la cual si bien las diferencias entre los Montague y los Capulet no eran culturales, sí eran sociales: veíamos a los padres de Romeo y de Julieta luchar contra la unión de los protagonistas debido a una enemistad familiar que venía de incontables años atrás. Shakespeare incluso se inspiró para su obra en una mucho más antigua: el poema Las metamorfosis, de Ovidio, terminado en el año 8 d.C. aproximadamente, en el cual los padres de los protagonistas también se oponen a la unión de estos (Halio y Richmond, 1998).

La historia contada en Romeo y Julieta se ha repetido muchas de veces en el cine, así sea de manera sutil. En la era moderna, encontramos el choque sociocultural en muchas películas clásicas como Grease (1978), West Side Story (1961), Orgullo y prejuicio (2005, basada en la obra de Jane Austen), Titanic (1997), entre otros dramas románticos que enfrentan a familias de mundos distintos. En el género de comedia romántica tenemos éxitos de taquilla como My Big Fat Greek Wedding (2002), nuestro principal referente, la cual recaudó US\$ 368,7 millones a nivel mundial en el año de su estreno, y un puntaje de $76 \%$ en Rotten Tomatoes. También consideramos Meet the Parents (2001), cinta en la cual una familia adinerada rechaza la idea de que su hija se case con un hombre de clase media (Ben Stiller); o Guess Who (2005), protagonizada por Ashton Kutcher, en la cual la familia afroamericana de su novia hace lo posible por separar a la pareja interracial. Más recientemente tenemos Crazy Rich Asians (2018), nuevamente enfrentando a ricos y pobres, la cual fue reconocida como la comedia romántica más exitosa de los últimos 10 años.

En el Perú, el tema de las diferencias socioculturales en romances y comedias también está presente en éxitos comerciales como la saga completa de ¡Asu mare!, en la 
cual Cachín (Carlos Alcántara), un hombre de clase baja limeña lucha por el amor y la aceptación de Emilia (Emilia Drago), una chica perteneciente a la adinerada y reconocida familia limeña Rizo-Patrón. A lo largo de las tres películas de la saga, las cuales han roto récords de taquilla en el Perú, el protagonista lucha contra su estatus socioeconómico y cultural, buscando la aprobación de Emilia (¡Asu mare!), luego de su familia (¡Asu mare! 2) y, finalmente, en la tercera entrega se mantiene esto como tema recurrente al intentar conseguir una visa para EE.UU. y comportarse a la altura de la familia de su esposa.

Esta temática se ve claramente reflejada también en la exitosa serie Al fondo hay sitio, de América Televisión, que tuvo ocho temporadas entre el 2009 y el 2016, y ganó los Premios Luces del diario El Comercio repetidas veces. La serie retrata la vida de los Gonzales, una familia ayacuchana que llega a vivir a Lima para consternación de los Maldini, una familia adinerada que vive en la casa de al lado. Lo que sigue son distintos encuentros, peleas, relaciones amorosas prohibidas y diversas situaciones que nacen de las diferencias culturales, económicas, sociales y raciales entre ambas familias. El éxito de la serie es innegable y ha motivado a varios estudios sociológicos. El mismo guionista, Gigio Aranda, comenta al respecto:

La importancia de haber llegado a tanta gente es algo muy extraño. O sea, tú nunca pensaste en eso, nunca pensaste que un programita en el que unos ricos y unos pobres viven frente a frente pudiera tener tanta importancia. Eso es irrepetible porque ya no podemos hacer ese tipo de programas. Si nos ha funcionado tanto es porque se apeló a una identificación maravillosa con la gente (Gigio Aranda: “"Al fondo hay sitio’ ha durado más de lo que debía durar", 3 de diciembre del 2016).

La serie cautiva los corazones del público por la identificación que pueden encontrar con cualquiera de las dos familias. El sociólogo Eduardo Arroyo Laguna opina que:

La serie creada por Efraín Aguilar trata sobre temas de nuestra vida cotidiana, de situaciones que podrían pasarle a cualquiera de nosotros, como son los problemas de exclusión y discriminación, ya sea por nuestra forma de pensar, el tamaño de nuestra nariz o si somos gordos o flacos ("Al fondo hay sitio": el boom televisivo más exitoso de todos los tiempos, 24 de diciembre del 2011). 
Según Arroyo Laguna, el éxito de las situaciones cómicas sale de la creación de personajes opuestos y de la representación que muestra a la audiencia. Se hacen críticas a la sociedad y se enseña al respecto, generando empatía entre el público.

Mediante la sátira uno toma conciencia, aunque puede verlo como un humor criollo nada más; sin embargo, podemos darnos cuenta de problemas de hace 5 siglos en nuestro país, como la disputa entre etnias en las que el inca dominaba sobre los demás hasta que con la llegada de los españoles aparece lo racial como predominante respecto a los quechuas y aymaras, etc. (“Al fondo hay sitio": el boom televisivo más exitoso de todos los tiempos, 24 de diciembre del 2011).

La serie surgió inspirada en un segmento del programa de comedia El especial del humor, en el cual dos vecinas racistas del distrito de La Molina debían convivir con un grupo de clase baja de Ate.

\subsection{Estructura}

Optamos por una dramaturgia clásica aristotélica de tres actos: planteamiento, nudo y desenlace. Según el enfoque del autor Robert Mckee (2009):

El diseño clásico implica una historia construida alrededor de un protagonista activo que lucha principalmente contra fuerzas externas antagonistas en la persecución de su deseo, a través de un tiempo continuo, dentro de una realidad ficticia coherente y causalmente relacionada, hasta un final cerrado de cambio absoluto e irreversible (pág. 67).

A este diseño, Mckee lo llama “arquitrama” y pone ciertos límites a su estructura, dentro de las infinitas posibilidades creativas de un guion o historia. Con esto en mente, reordenamos nuestra historia para que no sea un montaje de escenas y secuencias arbitrarias. Cada escena debía llevarnos a la siguiente de manera estratégica, orgánica y real. Las consecuencias de los acontecimientos narrativos debían hacer escalar el conflicto y no parecer situaciones independientes a lo largo de 90 minutos. El guion se desenvuelve de manera orgánica según las acciones que van tomando nuestros protagonistas y antagonistas: una acción lleva a una reacción que termina por mejorar o 
empeorar la situación de nuestra pareja estrella. Estas causalidades son las que nos ayudaron a que la historia completa esté conectada y no sea una lista de situaciones cómicas sin ninguna relación en particular entre sí.

Tal como refiere Margaret Atwood (Masterclass, s/f), en el diseño clásico de un relato, todas las preguntas que plantee la historia deben ser respondidas de manera que el público no se quede con dudas; los problemas se solucionan y los misterios se resuelven. Made in Perú cierra con un clásico final feliz: Jake y Natalia se casan, Jake logra la aceptación de Aurelio, Mercedes y Natalia arreglan sus diferencias, y Max deja de ser una amenaza. En otras palabras, todos los problemas y conflictos presentados a lo largo de la historia se solucionan y no quedan espacios para dudas ni interpretaciones de lo que depara el futuro. Un "felices por siempre”, clásico y directo.

Por su parte Judd Apatow, comediante y productor de un gran repertorio de comedias americanas exitosas, opina que la gran mayoría de películas, si no todas, están estructuradas de la misma manera. Por más extraña que parezca o pueda llegar a ser, la historia siempre contará con tres actos y tendrá diferentes etapas:

Presentarás a los personajes, tendrás que explicar el mundo en el que estás y las reglas de este mundo y, en cierto punto, quieras o no, introducirás un problema. Y luego, en algún momento, ese problema empeorará. Más adelante, o ese problema se solucionará o le dispararás a ese sujeto en la cabeza, y luego terminará todo. Así que realmente no hay tantas maneras de hacerlo (Masterclass, s/f).

La comedia, en particular, cuenta con una serie de elementos que la estructuran dentro de ciertos parámetros y que, es evidente, se cumplen una y otra vez. Steve Kaplan habla de la estructura de un guion de comedia en una entrevista para:

Si has visto Star Wars, has visto un gran ejemplo del clásico viaje del héroe [...]. Hay estructuras muy parecidas en la comedia, pero muchas diferencias importantes también [...]. En el viaje del héroe cómico, empieza como el clásico en su mundo ordinario. Vemos a nuestro protagonista, sea Bill Murray en Groundhog Day o Melissa McCarthy en Spy, pero la diferencia está que mientras el héroe clásico tiene una grandeza interior de la que puede no ser consciente, el héroe cómico no tiene ninguna grandeza; son incluso medio desastrosos [...]. Empiezas con un personaje roto o con 
defectos, con un vacío interior, pero no lo saben; están felices en su mundo

(Film Courage, 15 de abril del 2017).

De esta manera, en todas las versiones decidimos que nuestro personaje principal, Natalia, sería mostrado en este estado "normal", como vive en EE.UU.; aparentemente se encuentra cómoda, pero siente un notorio rechazo enorme hacia su familia y el Perú.

Kaplan también menciona cómo el comic hero journey se diferencia del classic hero journey en cuanto a las metas de los personajes. Mientras que los héroes de las comedias se resistirán en todo momento a cambiar sus metas iniciales, los personajes del classic hero journey estarán dispuestos a emprender el "viaje".

De esta manera, planteamos a Natalia como un personaje que, incluso estando en Perú y cuando la realización del matrimonio estaba pactada para realizarse en Lima, ella continuaba negando la situación, intentando volver o tratar de realizar todo lo más parecido a sus planes iniciales.

Un hecho anecdótico fue que, durante el feedback, tuvimos comentarios mixtos acerca de la secuencia del correo electrónico que Jake escribe a sus padres, sobre lo acontecido en Perú, y en el cual opina sobre lo que diferencia a los peruanos de los estadounidenses, así como de la secuencia del musical en el centro de lima. Por un lado, todas aquellas personas con algún tipo de formación o experiencia en audiovisual nos comentaron que el correo era un recurso cliché; además, les pareció que ambas secuencias no aportaban nada a la historia y que detenían la trama innecesariamente. Por otro lado, todas aquellas personas que no tenían ningún tipo de conocimiento teórico audiovisual quedaron encantadas con ambas secuencias; incluso las resaltaron como sus partes favoritas. Por ello, decidimos mantener ambas.

\subsection{Comedia visual}

La comedia visual o sight gags es una manera de hacer comedia que utiliza como recurso la música, las transiciones, los movimientos de cámara y los planos ampliamente creativos y distintivos. En la época del cine mudo, específicamente en el slapstick de Buster Keaton y Charles Chaplin, los gags visuales eran la única forma de hacer comedia. 
Con la llegada del sonido al cine, muchos de estos gags visuales han disminuido o se han perdido un poco en la transición hacia un cine "más hablado". Podríamos rescatarlos en el cine satírico de los Monty Python, y hoy en día están volviendo a ser una de las principales formas de comedia gracias a directores como Quentin Tarantino, Taika Waititi y Edgar Wright.

En el video Edgar Wright: How to Do Visual Comedy, de 2014, Tony Zhou analiza la comedia visual a partir de ejemplos creativos para contar historias simples:

[Muchas películas cómicas modernas] son improvisaciones editadas a la ligera. Todos están parados y se hablan unos a otros en close-up. Casi ninguno de los chistes es visual [...]. Es solo diálogo. Y es triste, porque eso es solo una fracción de lo que se puede hacer en el cine. Además de la animación y algunos comerciales, la comedia visual ha retrocedido (Every Frame a Painting, 27 de mayo del 2014).

Edgar Wright es, sin duda, uno de los mayores referentes en comedia y es reconocido mundialmente por eso. Diversas revistas digitales sobre filmmaking, como Vulture, Indiewire y No Film School, refieren a Wright directamente cuando se habla de comedia visual, elogiando a sus películas. Y es que en su repertorio filmográfico encontramos películas como Hot Fuzz (2007), la cual recaudó US\$ 80,7 millones en el Box Office americano y obtuvo 91\% de aceptación de las críticas en Rotten Tomatoes ( $89 \%$ de la audiencia); Shaun of the Dead (2004), la cual es considerada hasta la fecha como una de las mejores comedias del milenio, con éxito de taquilla doméstica por US\$ 30 millones y 92\% de crítica en Rotten Tomatoes (93\% de la audiencia). Su última película, Baby Driver (2017) recaudó US\$ 226,9 millones en el Box Office doméstico y logró un 93\% de aceptación por la crítica en Rotten Tomatoes. Con estas cifras, podemos decir que Edgar Wright es, por excelencia, la cara de la comedia visual en la actualidad.

Eso no deja de lado a genios como Quentin Tarantino. Si bien sus películas tienen un corte más dramático, no deja de utilizar gags visuales para aligerar su narrativa. Desde Reservoir Dogs (1992), Pulp Fiction (1994) y, más recientemente, películas como Inglourious Basterds (2009), Django Unchained (2012), The Hateful Eight (2015) y Once Upon a Time in Hollywood (2019), Tarantino logra un buen balance entre la comedia hablada — los diálogos de sus personajes son geniales — y la comedia visual. Su última película, si bien no ha sido la más exitosa - la sobrepasan Inglourious Basterds en primer 
puesto y Django Unchained en segundo según Box Office Mojo y Variety-, ha recaudado US\$ 366,8 millones a nivel mundial.

La comedia visual, si bien no es la forma más común de hacer comedia, es sin duda una de las corrientes que se ha ganado el corazón del público. En el Perú, ha probado funcionar bien en películas como ¡Asu mare! 3, la cual llevó al cine a más de dos millones de espectadores, y en productos de contenido digital más juveniles como los de las plataformas Buzzfeed, College Humor, Enchufe Tv, o los videos de los bloggers Gerardo Pe, Benjadoes, Ximena Galiano, Mateo Garrido-Lecca, entre otros.

Aunque incluir elementos visuales específicos es una tarea que suele hacerse durante la escritura del guion técnico, decidimos incorporar algunas secuencias donde jugamos con este estilo para darle más intensidad a la comedia. Por ejemplo, en las secuencias de los viajes de EE.UU. a Lima utilizamos el recurso de los quick cuts como lo hace Wright (en Hot Fuzz, por ejemplo), convirtiendo así una acción aburrida y común en una secuencia mucho más dinámica que pueda capturar la atención del público. Utilizamos match-cuts, es decir, cortes secos de una escena a otra por medio de planos de similar composición para cambios de escena drásticos; entradas y salidas del plano de manera divertida (Gabriela entregándole una copa de champán a Natalia mientras vemos su expresión de consternación durante su shower de novia), y otros recursos como el uso de efectos de sonido en el momento correcto, descubrimientos por paneo, muchas veces utilizados para descubrir a la abuela en alguna situación extraña y graciosa, entre otros.

Todos estos recursos han sido utilizados por los genios de la comedia visual y han probado ser útiles y distintivos.

\subsection{Venta del guion}

En la etapa de venta, podríamos decir que tuvimos la suerte de nuestro lado. Sin saber realmente cómo funcionaba el mercado de guiones cinematográficos comerciales, acudimos a personas de nuestro entorno profesional que potencialmente podrían ser de ayuda al momento de buscar a un comprador.

Inscribimos el guion como obra de autoría conjunta en la dirección de derechos de autor de Indecopi y se lo enviamos a Roxana Rivera, productora de Prisma 
Producciones, quien ha producido películas renombradas como las tres cintas pertenecientes a la saga de ¡Asu Mare!, A los 40, Av. Larco, Locos de amor, Calichín, entre otras, y quien además había trabajado mano a mano con Tamara Bravo en diversas producciones publicitarias de Cine 70. Roxana interesó desde el inicio y nos ofreció buscar ella misma a quien quisiera dirigir nuestra película.

En paralelo, enviamos el guion a Martha Fuentes, coordinadora de distribución de Tondero, quien había sido supervisora y jefa directa de Tamara cuando trabajaron en la productora cinematográfica Cinecorp. Martha leyó y compartió el guion con Milagros Valladares, gerente administrativa de Tondero, y ambas se interesaron en comprar el guion y producirlo dentro de la empresa.

Finalmente, la venta se dio con Roxana, pues su propuesta era más inmediata e implicaba menos tiempo para producir, filmar y estrenar. Se unió con Mauricio Torres Bohl, director de promociones de América Televisión, quien será productor y director del proyecto.

Tuvimos un poco de reparo al aceptar a un director de publicidad sin experiencia en cine comercial, ya que nuestra futura película contaba con factores que considerábamos difíciles de manejar: una amplia gama de personajes, de los cuales algunos deben hablar inglés como primer idioma y no entendían bien el español, manejando un código de comedia visual que era de suma importancia para nosotras. Afortunadamente, tuvimos la oportunidad de conocer a Mauricio antes de cerrar la venta y pudimos calmar nuestras dudas y preocupaciones, al descubrir que su sentido del humor y profesionalismo iban acorde con nuestras aspiraciones y nuestra visión.

\subsection{Firma de contrato y cierre de venta}

Antes de vender el guion, lo inscribimos en Indecopi vía on-line. El proceso es fácil de realizar; sin embargo, para nosotras fue un poco más complejo ya que, al ser dos autoras, una de nosotras tuvo que firmar una sucesión intestada en una notaría para poder inscribirlo a nombre de ambas. Otro detalle fue que el guion se inscribió bajo el concepto de obra literaria, ya que no existe a la fecha el concepto de "guion cinematográfico". 
La firma del contrato demoró alrededor de un mes. Tuvimos varias idas y vueltas en la negociación de las condiciones. Además, tuvimos algunas dificultades para encontrar un abogado que nos asesore en el tema, debido a que no muchos tienen expertise en derechos de autor y cesión de derechos de obras. Por eso, Tamara Bravo pidió a su tío Gonzalo Rodríguez Risco, dramaturgo y guionista, una copia de los formatos de contrato que suele utilizar, con lo cual decidimos incorporar algunos elementos al contrato ya existente.

Algunos de los puntos que pudimos incluir en la negociación final fueron los siguientes:

\section{CLÀUSULA PRIMERA.- ANTECEDENTES}

1. LA PRODUCTORA elaborará una obra cinematográfica denominada MADE IN PERÚ.

2. El guion de la película denominada MADE IN PERÚ ha sido elaborado, en forma conjunta para LA PRODUCTORA, por ANAIS CHAMPIN VIDAL y TAMARA MARÍA BRAVO LEMBCKE, LAS COGUIONISTAS, constituyendo una obra colectiva de titularidad de las personas mencionadas, cuyos derechos patrimoniales serán administrados en forma exclusiva por LA PRODUCTORA a partir de la firma de este contrato, quien a su vez, queda facultada para administrar los derechos morales sobre el guion, de conformidad con lo establecido en el artículo 15 del Decreto Legislativo 822 y modificatorias.

3. A efectos del presente contrato, la obra audiovisual, será denominada indistintamente, también como PELÍCULA o LARGOMETRAJE.

\section{CLÁUSULA DÉCIMO SEGUNDA.- VIGENCIA Y FECHA LÍMITE}

La vigencia del presente contrato es a perpetuidad siempre y cuando se realice la película en los próximos 5 (cinco) años, de lo contrario, los derechos regresan a LAS GUIONISTAS sin devolución alguna del dinero pagado por los mismos. 


\section{CLÁUSULA DÉCIMO TERCERA.- ÁMBITO GEOGRÁFICO Y}

NUEVAS PLATAFORMAS

LAS GUIONISTAS acuerdan que su autorización no tiene ámbito geográfico definido, y que autoriza toda traducción que se hagan sobre el guion y futura obra audiovisual.

Adicionalmente, LA PRODUCTORA se obliga a negociar un monto adicional a pagar a LAS GUIONISTAS si es que la película producto del guion, se incorpora a nuevas plataformas digitales como Netflix u otros.

\subsection{Reescritura con el director}

Para la reescritura del guion, programamos reuniones semanales con el director Mauricio Torres Bohl.

En relación con los protagonistas, se puso más énfasis en la relación de Natalia con su papá, para darle un arco más pronunciado a sus personajes y enriquecer el conflicto central de la historia. Además, el conflicto con Aurelio se hizo más intenso con Jake, dándole a este último un rol menos pasivo en la historia. Por ello mismo, se le dio un papel más protagónico a Max. En la nueva versión que reescribimos con Mauricio, añadimos una escena en la que Aurelio lleva a todos a su casa para marcar más la incomodidad y los celos de Jake.

Se trabajó a los personajes secundarios más de cerca, para poder diferenciarlos entre sí, especialmente con la familia extensa de Natalia. Sin embargo, sus estilos de arquetipos fueron similares a las versiones anteriores.

Por otro lado, teníamos un problema con el excesivo número de páginas. por lo cual tuvimos que reducir el tamaño de varias secuencias y suprimir algunas escenas. Los cambios más relevantes estuvieron en las escenas del shower de la novia y de la cena para conocer a los papás de Jake, que se fusionaron en una sola, y la secuencia del correo electrónico de Jake se hizo más corta. 
Para reducir gastos de producción y logística, se decidió eliminar algunos personajes - como los amigos de Jake, que salían al inicio, y los hijos de Juanca y Delia-. Además, se eliminó la secuencia musical de Jake y Natalia.

Tabla 3.1. Cambios en los personajes en diferentes versiones del guion

\begin{tabular}{|c|c|c|}
\hline Per & Versión previa a la venta & Versión final \\
\hline Nat & $\begin{array}{l}\text { Natalia era productora de } \\
\text { audiovisuales, era controladora y algo } \\
\text { obsesiva; quería que todo sea a su } \\
\text { manera. Su personalidad era voluble, } \\
\text { pues pasaba de ser fuerte y decidida a } \\
\text { tener miedo de enfrentar a sus padres. } \\
\text { El amor a su familia era invisible; se } \\
\text { lo manifestaba a Jake a través de } \\
\text { palabras, pero no era hasta el } \\
\text { desenlace que se lo transmitía a sus } \\
\text { padres. }\end{array}$ & $\begin{array}{l}\text { Natalia mantuvo muchos de los aspectos } \\
\text { iniciales, solo que con una motivación más } \\
\text { fuerte: alejarse de su familia conservadora } \\
\text { la había convertido en una mujer fuerte e } \\
\text { independiente, pero regresar a sus raíces } \\
\text { hacía que retroceda en su proceso y tenga } \\
\text { miedo a enfrentar a su madre. Su cariño } \\
\text { hacia su papá se hace más evidente y su } \\
\text { conexión con Jake también, siendo la } \\
\text { música un factor importante en la vida de } \\
\text { los tres. Su lucha interna entre su futuro y } \\
\text { su pasado toma una nueva forma al no } \\
\text { rechazar del todo a sus raíces, pero sí } \\
\text { querer una vida distinta para su } \\
\text { matrimonio. }\end{array}$ \\
\hline Jake & $\begin{array}{l}\text { Jake era financista, ordenado y } \\
\text { pulcro. Su origen estadounidense lo } \\
\text { hacía un hombre apegado a las reglas, } \\
\text { calculador y sereno. No sabía hablar } \\
\text { español, lo que dificultaba sus } \\
\text { intentos por relacionarse con la } \\
\text { familia de Natalia. La rivalidad entre } \\
\text { Jake y Aurelio, si bien era evidente, } \\
\text { no era muy directa, puesto a que se } \\
\text { basaba en un tema de xenofobia que } \\
\text { Aurelio solo transmitía a su familia, } \\
\text { mas no a Jake directamente. }\end{array}$ & $\begin{array}{l}\text { Jake dejó de ser apegado a las reglas y pasó } \\
\text { a ser músico, hijo de hippies liberales, lo } \\
\text { que lo pone en una contraposición más } \\
\text { divertida y marcada frente a la familia } \\
\text { latina conservadora de Natalia. Jake sabe } \\
\text { hablar español, lo que lo vuelve más activo } \\
\text { a la hora de intentar ganarse el afecto de } \\
\text { estos, así no maneje bien el lenguaje } \\
\text { coloquial peruano. Su torpeza hace más } \\
\text { evidente la razón del rechazo de Aurelio, y } \\
\text { lo lleva a participar más para ganar su } \\
\text { aprecio. }\end{array}$ \\
\hline Mercedes & $\begin{array}{l}\text { Mercedes era un ama de casa } \\
\text { conservadora de bajo intelecto que } \\
\text { hacía comentarios fuera de lugar, los } \\
\text { cuales confundían a la gente a su } \\
\text { alrededor. Sus intenciones de } \\
\text { organizar la boda de su hija eran } \\
\text { inocentes y proactivas, y resultaban } \\
\text { un caos. }\end{array}$ & $\begin{array}{l}\text { Mercedes, si bien no tiene un conocimiento } \\
\text { extenso sobre temas actuales, no es } \\
\text { necesariamente de bajo intelecto. Es } \\
\text { controladora, la cabeza del hogar, es } \\
\text { machista y manipuladora. Es metiche y más } \\
\text { controladora que Natalia. Sus intenciones } \\
\text { de organizar la boda se convierten en un } \\
\text { esfuerzo más egocéntrico por ser la } \\
\text { matrona de la familia, lo cual la pone en } \\
\text { una situación más poderosa sobre Natalia. } \\
\text { Su conflicto con su hija se hace más } \\
\text { evidente y orgánico. }\end{array}$ \\
\hline
\end{tabular}




\begin{tabular}{|c|c|c|}
\hline Aurelio & $\begin{array}{l}\text { Los intentos de Aurelio por alejar a } \\
\text { Jake de Natalia se basaban en planes } \\
\text { y conspiraciones, y si bien } \\
\text { demostraba su disgusto a su esposa } \\
\text { Mercedes, lo cierto es que no había } \\
\text { una relación directa entre él y su } \\
\text { futuro yerno que haga evidente su } \\
\text { rechazo. Su plan era traer a Max, un } \\
\text { peruano exnovio de Natalia, para } \\
\text { dirigir la atención de su hija en otra } \\
\text { dirección y alejarla del chico } \\
\text { extranjero y desconocido, pero su } \\
\text { trato directo a Jake era pasivo y casi } \\
\text { inexistente. Además, era gruñón a lo } \\
\text { largo de toda la historia y no era } \\
\text { empático con ningún otro personaje. }\end{array}$ & $\begin{array}{l}\text { Aurelio pasó a ser un hombre de familia, } \\
\text { gruñón de todos modos y serio, pero con un } \\
\text { gran amor por sus seres cercanos. El arribo } \\
\text { del novio extranjero de su hija mayor } \\
\text { amenaza su ideal de unión familiar, lo que } \\
\text { hace más evidente su rechazo hacia Jake. } \\
\text { Su actitud es ruda y orgullosa frente a él, y } \\
\text { algo más cálida con el resto. Es más } \\
\text { evidente su amor por su hija mayor, y al } \\
\text { convertirlo en un apasionado por la música, } \\
\text { les hicimos un lazo más fuerte. Aurelio es } \\
\text { necio, pero no más que Natalia y Mercedes, } \\
\text { por lo que termina por acceder a los deseos } \\
\text { de su familia. }\end{array}$ \\
\hline
\end{tabular}

Fuente: Elaboración propia

Podemos afirmar que los cambios hechos para la versión final del guion son fruto de una discusión, con un peso equitativo por parte de las guionistas y el director. Si bien la visión del último fue un factor determinante al momento de tomar decisiones, era importante que la esencia de la idea original se mantuviera, por lo cual, como guionistas, nos reservamos el derecho de aplicar cambios que no perjudiquen la historia. Comprendiendo los límites de presupuesto, producción y narrativa, entendimos que era necesario cortar, modificar y reemplazar algunas escenas para poder repotenciar lo que ya estaba escrito. Situaciones que necesitaron cambios fueron conversadas con detenimiento, a veces rápidamente y otras veces, durante días, para encontrar el reemplazo perfecto que satisfaga a ambas partes.

Escenas como la del musical, una secuencia romántica y divertida, que mostraba un lado alegre y colorido de la peruanidad — más específicamente, la vida en Lima-, y la versión original de la carta de Jake a sus padres - un collage de situaciones clásicas en el día a día entre jergas y coloquialidades locales-, fueron tal vez las secuencias que más nos costó eliminar. El musical daba un respiro a las situaciones tensas de nuestros protagonistas y los mostraba en un contexto sin problemas, para desarrollar mejor la relación de pareja y ganarse el cariño del público. Finalmente, fue reemplazada por una escena que profundizaba en la complejidad de la relación entre Natalia y su padre. Con los demás cambios hechos en la historia, el amor que Natalia y Jake se tenían era evidente de manera orgánica, con detalles en cada escena, por lo que una secuencia larga y musical 
solo ponía una pausa a la narrativa, llevándola así a su eliminación. En cuanto a la carta, si bien se mantuvo la idea, en un principio la escena era más larga y divertida. Dado que cada uno de los insertos sería un plano más pata grabar en diversos espacios con cada uno de los personajes, además de agregar varios minutos a la película que ya de por sí tendría un metraje extenso, se optó por reducirla, lo cual tuvimos que aceptar a pesar de ser una de nuestras secuencias favoritas.

Por otro lado, mantuvimos nuestra postura en decisiones como mantener una gran cantidad de personajes secundarios, a pesar de ser potencialmente una complicación tanto en presupuesto como producción, pues una familia reducida no tendría el mismo impacto en el contexto de la familia criolla "choclona" y entrometida que tenemos en la versión final del guion.

Estas, entre otras decisiones y cambios, llevaron a repotenciar nuestro guion, manteniendo nuestra esencia como guionistas y autoras de la historia, y a la vez adecuándonos al estilo del director, con mayor experiencia y conocimiento de nuestro público objetivo. 


\section{LECCIONES APRENDIDAS}

\subsection{Problemas en la estructura}

Se nos hizo muy fácil crear las situaciones de comedia. De hecho, empezamos el guion escribiendo todas las ideas de gags que teníamos. Sin embargo, nos centramos tanto en esa parte que descuidamos mucho la estructura y el problema central de la historia.

Esto hizo que demoráramos mucho en conciliar la historia con todo lo que habíamos pensado, ya que reescribimos la historia muchas veces y nos ordenamos con una escaleta muy tarde. Como comenta William M. Akers (2008), aprendimos que el guion es un trabajo en el que se deben balancear cuidadosamente las partes más duras o lógicas, tales como estructurar el orden de la historia y los momentos más creativos, desordenados o espontáneos, en los cuales se aterrizan las situaciones concretas de comedia o los diálogos.

\subsection{Herramientas útiles}

Encontramos que trabajar un guion entre dos personas se nos hizo más fácil en un documento compartido que en los programas de redacción de guion típicamente utilizados.

Fue de mucha utilidad tener un documento con el avance del guion, otro con el desarrollo de la escaleta y uno más con notas sueltas de situaciones, gags y diálogos que creábamos espontáneamente, sin tener un lugar claro dónde colocarlos, pero que queríamos conservar de todos modos.

Por otro lado, hacer el ejercicio de imprimir el guion, releerlo y tomar notas en papel fue, en algún momento, necesario para tener mayor claridad de los errores y aciertos. 
También utilizamos herramientas más visuales, como pizarras o notas adhesivas, que nos ayudaron a tener una visión más clara de las etapas de la historia, el cambio de los personajes en cada acto y sus objetivos. Esto fue clave, especialmente en la última etapa, en que solo teníamos que reestructurar la historia. Probablemente hubiera sido ideal utilizar estas herramientas desde un principio, para tener un orden más claro de los plots por cada personaje.

Al final del feedback y los cambios del director, utilizamos Studio Binder para colocar el guion en el formato clásico, para que la productora pueda hacer el desglose de producción sin problemas.

\subsection{Literatura sobre el tema}

Encontramos que muchos de los libros más conocidos sobre la teoría del guion clásico, como Story: Substance, Structure, Style, and the Principles of Screenwriting, de Robert McKee, o El guion de ficción audiovisual, de Augusto Tamayo, nos ayudaron a recapitular los fundamentos de la redacción de un guion. Pero fueron insuficientes en algunos momentos o para resolver dudas específicas. Además, si bien exponían claramente la estructura para un drama, encontramos difícil aplicarla para una comedia.

Para poder entender mejor cómo funcionaba la estructura del guion aplicada específicamente a una comedia, nos sirvió mucho la novedosa estructura que plantea Blake Snyder (2008) en Save the Cat! The Last Book on Screenwriting You'll Ever Need. También nos sirvieron algunos apuntes que hizo Steve Kaplan en una entrevista para Film Courage (15 de abril del 2017), en la cual daba consejos para estructurar la historia específicamente en las comedias.

Para ahondar en los arquetipos de los personajes principales y de los "villanos", utilizamos los libros The Complete Writer's Guide to Heroes and Heroines: Sixteen Master Archetypes, de Tami D. Cowden, Carolyn LaFever y Sue Viders; y Fallen Heroes: Sixteen Master Villain Archetypes, de Tami D. Cowden.

Para tener más clara la metodología y el orden de trabajo, vimos el blog The Bitter Script Reader, creado por un estadounidense anónimo que trabaja en Hollywood 
leyendo guiones. Nos sirvieron sus videos 12 Step Screenwriting de su canal de YouTube.

Para poder aprovechar mejor las situaciones de comedia, vimos algunos videos del Masterclass Video Lessons and Class Workbook, como los de Steve Martin Teaches Comedy, Judd Apatow Teaches Comedy y los videos del canal Every Frame a Painting, como el de Edgar Wright: How to do Visual Comedy.

Por un lado, documentarnos tanto nos ayudó a entender mucho mejor el trabajo que queríamos hacer; pero, por otro lado, nos tomó bastante tiempo $\mathrm{y}$, en algunos momentos, las fuentes se contradecían parcialmente entre ellas.

Además, una práctica que nos ayudó a interiorizar más rápidamente los conocimientos sobre estructura y argumento fue ver películas con temáticas similares. Algunas de las más importantes fueron: My Big Fat Greek Wedding (2002), Father of The Bride (1991), Meet The Parents (2000), Bridesmaids (2011), Guess Who (2005), entre otros.

\subsection{Venta de guion}

Como no existe ninguna vía formal para presentar y vender guiones en nuestro país, vimos necesario inscribirlo previamente en Indecopi, para evitar cualquier tipo de mala experiencia. Inscribirlo es un trámite relativamente fácil; se puede hacer mediante la página web y con pago on-line.

Sin embargo, este solo se puede inscribir como obra literaria, ya que la categoría "guion" no existe. Desconocemos las implicancias de este vacío legal y nos fue imposible encontrar algún abogado familiarizado con la industria cinematográfica. Esto también complicó la firma del contrato una vez realizada la venta. Tuvimos que hablar con otros guionistas o cineastas para comparar los términos del contrato e incluir algunas cláusulas intuitivamente, pero nos hubiera gustado tener la asesoría legal pertinente.

Somos conscientes de que tuvimos suerte al vender este guion. Se hizo de forma rápida y al primer intento. Dado que vivimos en un país con una industria cinematográfica poco profesionalizada, reconocemos que fue clave tener contactos en el rubro. Tamara 
Bravo, gracias a su experiencia audiovisual, conocía a varios directores y productores que nos guiaron, dieron feedback y, en última instancia, compraron el guion.

Al presentarlo, encontramos rápido interés por parte de dos productoras y creemos que esto se debió a los temas que abordaba el guion: la historia de amor entre una peruana y un extranjero, el choque cultural de las familias, las situaciones que exacerbaron las costumbres nacionales, los arquetipos familiares, entre otros. Todos son temas que cualquier peruano promedio reconoce, entiende y puede gustar. Lo que, en términos comerciales, se traduciría en una película que podría tener amplia recaudación. Vender un guion con otro tipo de temáticas más particulares u originales sería más difícil.

Algunos temas que no resultaron atractivos para la venta fueron la gran cantidad de personajes que había, el gran número de páginas —que implicaban más minutos de grabación - y algunas dudas con respecto al juego de inglés y español en el guion — por lo que en la reescritura se trató de quitar, en la medida de lo posible, la mayor cantidad de diálogos en inglés-. Sin embargo, para la productora, todos estos fueron temas que fácilmente podrían cambiarse en la reescritura del guion, en la cual ajustamos la longitud del mismo, eliminamos personajes secundarios innecesarios y escenas que, en términos de producción, resultarían muy caras — como la secuencia musical—. Al respecto, fue fundamental mostrar nuestra disposición para hacer los cambios necesarios al guion.

\subsection{Consideraciones del feedback}

Durante el proceso recibimos el feedback de diferentes personas, tanto del rubro de comunicaciones y audiovisuales como de otras carreras u ocupaciones. Tuvimos que tomar con pinzas muchos comentarios, considerando el background de las personas. Por ejemplo, algunos del rubro de audiovisual tuvieron comentarios algo sesgados, ya que tenían predilección por películas más independientes e hicieron varios comentarios que nos recomendaban eludir el cliché y prescindir de secuencias que, según ellos, no aportaban a la historia. Pero esto se veía contrastado con los comentarios de las personas que no trabajan en el rubro audiovisual y que, por el contrario, consideraban esas escenas o secuencias "cliché" como sus favoritas. También recibimos comentarios de un profesor de la universidad, quien comentaba que tenía problemas éticos con el guion, ya que encontraba que podía percibirse como discriminatorio debido a los gags que se burlaban 
mucho de la peruanidad. Creemos que fue positivo tomar feedback no solo de especialistas en el rubro sino también de personas que no lo eran, quienes, al fin y al cabo, dada la naturaleza comercial o popular del guion, son el público objetivo final de la película a realizarse. 


\section{LOGROS Y RESULTADOS}

La venta del guion y el cierre del contrato constituyen un logro fundamental a partir de los objetivos que nos habíamos trazado. Sin embargo, quisimos buscar opiniones de profesionales de distintas orillas del negocio, a fin de obtener una ponderación del producto y la versión final del guion. Entre Estas, resaltan tres opiniones de perfiles diversos: de Cesar Loli, dramaturgo, guionista y docente de la Universidad de Lima y la PUCP; Gonzalo Rodríguez Risco, renombrado dramaturgo y guionista con estudios en universidades internacionales de alto nivel y con varias películas comerciales en su cartera; y Martha Fuentes Bustamante, coordinadora de distribución de la empresa Tondero, a quien consideramos una confiable fuente de información sobre el mercado cinematográfico comercial al que se está apuntando.

\section{Cesar Loli}

\section{Dramaturgo y guionista}

\section{Docente de la Universidad de Lima /PUCP}

"Debo felicitarlas por el buen manejo narrativo. En el guion demuestran competencias profesionales sobre el tema. La estructura narrativa es clara y creo que fácilmente sustentable con el paradigma de Syd Field, con McKee, Doc Comparato, Linda Seger, entre otros autores. También hay buen manejo del género, en varias partes me han hecho reír. Dicho esto, me siento incómodo debido al mensaje. Sé que el género de la comedia se basa, en gran parte, en reírse de uno mismo; sin embargo, me parece que en la historia se llega a la 'caricaturización' negativa de lo peruano. Creo que, como comunicadores, debemos tener cuidado con este tipo de mensajes, que tienen mucho que ver con la mirada que tenemos, como sociedad, de nosotros mismos. Esto no ocurre con otros países de la región. No es lo mismo, por ejemplo, mostrar al extranjero que no se adapta a la rica cultura peruana - como comer cuy o ají- que mostrar a los peruanos con costumbres de mal gusto — como la imagen de la esposa arreglándose el juanete o el perfil, en general, de muchos de los personajes-." 


\section{Gonzalo Rodríguez Risco \\ Dramaturgo y guionista}

\section{MFA en Dramaturgia - Yale School of Drama}

"Made in Perú, de Anaís Champin, Tamara Bravo y Mau Bohl, se coloca perfectamente dentro del género de comedia romántica y dentro del subgénero de 'pez fuera del agua', lo cual es bastante original, ya que nos da una visión —en formato de comedia - de las idiosincrasias peruanas desde el punto de vista de un estadounidense y de una peruana separada, por voluntad propia, de sus raíces. La comedia está en el contraste. Como público, vamos presenciando un tren que se descarrila en cámara lenta ante nuestros ojos y, como corresponde al género, aunque sabemos que eventualmente el amor triunfará, el camino es bastante entretenido. Desde el punto de vista de los personajes, recomendaría un trabajo más profundo de los antagonistas, representados por el padre y el exenamorado. El primero tiene un cambio algo precipitado y el segundo se resuelve con un chiste un poco trillado. Por otro lado, la relación entre los protagonistas se sostiene, se resquebraja y se vuelve a construir de forma natural, y el rol de sidekicks de la hermana y el primo son muy divertidos. En general, se nota un guion bastante solvente, la base para una buena y divertida comedia romántica, y una que a la vez habla de nuestras costumbres y de nuestra idiosincrasia de forma original."

\section{Martha Fuentes Bustamante \\ Coordinadora de distribución de Tondero}

"Made in Perú es una comedia refrescante que utiliza bien la representación y la identidad peruana para generar diversas situaciones graciosas. Tiene un alto potencial comercial, ya que son el género de comedia y la representación peruana lo que jala mayores números de espectadores en el país actualmente. Los personajes, por más que pueden ser algo exagerados, son relacionables, divertidos $\mathrm{y}$, muchos de ellos, conmovedores. Natalia, la protagonista, no es perfecta, pero genera empatía por su lucha interior y por el tormento que le genera su familia, un tormento por el que muchos de 
nosotros hemos pasado en mayor o menor medida, y lleva a la identificación. Jake, el ajeno a nuestra realidad, se hace querer tanto como el resto de personajes por su torpeza y ternura, lo que hará que el público quiera ver a Jake y Natalia juntos al final. La comedia visual es algo que está en pleno auge y la han manejado bien. La historia sigue una línea orgánica y fácil de entender, lo que mantendrá al público atento en todo momento. Como crítica, diría que la gran cantidad de personajes podría traer problemas por temas de producción y presupuestos, por lo que tendría que manejarse bien el casting; es indispensable contar con algunas caras conocidas (celebrities), pero también introducir caras frescas. Además, el guion necesita pulirse un poco, ya que parece durar más de dos horas; tendrán que evaluar bien, ya sea a la hora de grabar o en edición, qué escenas son indispensables y de cuáles se pueden deshacer para que la película no sea demasiado larga y canse al público.” 


\section{REFERENCIAS}

Akers, W. M. (2008). Your screenplay sucks! 100 ways to make it great. Studio City: Michael Wiese Production.

"Al fondo hay sitio": el boom televisivo más exitoso de todos los tiempos (24 de diciembre del 2011). La República. Recuperado de: https://arepublica.pe/tendencias/599756-al-fondo-hay-sitio-el-boomtelevisivo-mas-exitoso-de-todos-los-tiempos/

Análisis de la taquilla del cine peruano del 2018 (7 de febrero del 2019). Cinencuentro. Recuperado de https://www.cinencuentro.com/2019/02/07/analisis-taquillacine-peruano-2018/

Antes se producían 5 películas al año, esto cambió gracias a las marcas (14 de junio del 2019). Mercado negro. Recuperado de https://www.mercadonegro.pe/mercadonegro-tv/tondero-cine-peruano-publicidad-marcas-peliculas-ano/

Apoyo \& Asociados (2018). Informe anual Cineplex S. A. (Cineplanet). Recuperado de: http://www.aai.com.pe/wp-content/uploads/2019/05/Cineplanet_Dic-18.pdf

Castro, R. (2017). "En ¡Asu mare! todos somos protagonistas”: Rituales de clase y distinción en el nuevo cine de entretenimiento peruano. Lima, Departamento de Ciencias Sociales. Recuperado de http://departamento.pucp.edu.pe/ciencias$\underline{\text { sociales/ }}$

Cine peruano: Más de la mitad de estrenos serán comedias (19 de enero del 2018). El Pirata. Recuperado de: https://elpirata.pe/2018/01/19/cine-peruano-mas-de-lamitad-de-estrenos-seran-comedias/

Conoce la nueva cadena de cines que iniciará operaciones en Perú (29 de junio de 2019). Perú Retail. Recuperado de: https://www.peru-retail.com/nueva-cadena-decines-iniciara-operaciones-peru/

CONFIEP (7 de diciembre del 2018). Esta es la evolución del cine en Perú. Recuperado de: https://www.confiep.org.pe/confiep-tv/esta-es-la-evolucion-del-cine-enperu/

El negocio del cine en provincias ha tenido un crecimiento "explosivo", según New Century Films (16 de noviembre de 2018). Gestión. Recuperado de https://gestion.pe/economia/mercados/negocio-cine-provincias-tenidocrecimiento-explosivo-new-century-films-nndc-250127-noticia/

Every Frame a Painting (27 de mayo del 2014). Edgar Wright - How to Do Visual Comedy [Archivo de video]. Recuperado de: https://vimeo.com/96558506

Film Courage (15 de abril del 2017). Screenwriting Structure: Race To The Finish by Steve Kaplan [Archivo de video]. Recuperado de https://www.youtube.com/watch?v=hXSPjo-Untk 
Gigio Aranda: “'Al fondo hay sitio' ha durado más de lo que debía durar” (3 de diciembre del 2016). Perú21. Recuperado de: https://peru21.pe/opinion/gigio-arandafondo-hay-sitio-durado-debia-durar-234920-noticia/

Halio, J. L. y Richmond, H. (editores) (1998). Shakespearean Illuminations: Essays in Honor of Marvin Rosenberg. Newark: U of Delaware P; London: Associated UP.

Herrera, J. (31 de diciembre de 2015). ¿De qué se ríen los peruanos y por qué? [Entrada en blog]. Humor S.A. Recuperado de: http://blogs.gestion.pe/humorsa/2015/12/de-que-se-rien-los-peruanos-y-porque.html

Huerta Mercado, A. (2004). "Ciudad abierta: lo popular en la ciudad peruana". En: Aramburú, C. E. et al, Las ciudades en el Perú. Lima, Centro de Estudios y Promoción del Desarrollo. Recuperado de: http://biblioteca.clacso.edu.ar/ar/libros/peru/desco/peruhoy06.pdf

Huerta Mercado, A. (2019). El chongo peruano. Antropología del humor popular. Lima: Estruendomudo.

Las marcas en el cine peruano (14 de setiembre de 2014). La República. Recuperado de https://arepublica.pe/marketing/818952-las-marcas-en-el-cine-peruano/

MasterClass (s/f). Judd Apatow Teaches Comedy. Masterclass. Recuperado de: https://www.masterclass.com/classes/judd-apatow-teaches-comedy

MasterClass (s/f). Margaret Atwood Teaches Creative Writing. MasterClass. Recuperado de: https://www.masterclass.com/classes/margaret-atwoodteaches-creative-writing

McKee, Robert (2009). Story: Substance, Structure, Style, and the Principles of Screenwriting. Nueva York: Methuen.

Peirano, L., y Sánchez León, A. (1984). Risa y cultura en la televisión peruana. Lima: Centro de Estudios y Promoción del Desarrollo

Tamayo, A. (2018). El guion de ficción audiovisual. Lima: Argos Productos Editoriales.

Snyder, B. (2007). Save the Cat! The Last Book on Screenwriting You'll Ever Need. Studio City, CA: M. Wiese Productions. 


\section{HIPERVÍNCULOS}

Google Drive: Guion en Word y PDF adjunto

https://drive.google.com/open?id=1U4VbUcTBxKGMT5fPA7H1cXWmmjuq5_zW 